Health Environments Research \& Design 7, no. 2 (2013): 29-56.

\title{
Space Allocation in the Award-Winning Adult ICUs of the Last Two Decades (1993-2012): An Exploratory Study
}

\author{
Author: \\ Mahbub Rashid, Ph.D., RA \\ Professor \\ School of Architecture, Design and Planning \\ University of Kansas \\ 1465 Jayhawk Boulevard \\ Lawrence, KS 66045 \\ P: 785.864 .4405 \\ F: 785.864 .5185 \\ mrashid@ku.edu
}




\title{
Space Allocation in the Award-Winning Adult ICUs of the Last Two Decades (1993-2012): An Exploratory Study
}

\begin{abstract}
This exploratory study describes space allocation among different generic categories of functions in adult intensive care units (ICUs), and shows how the amount of space of any one functional category is related to that of another functional category in these ICUs. It also shows how different strategic choices, such as size, construction type, specialty type and layout type, affect space allocation in these ICUs. The study includes a set of 25 adult ICUs that were awarded between 1993 and 2012 by the Society of Critical Care Medicine (SCCM), the American Association of Critical Care Nurses (AACCN), and the American Institute of Architects/Academy of Architecture for Health (AIA/AAH) for their efforts to promote healing of the critically ill and injured patients through the design of the critical care unit environment. The study finds notable differences in space allocation among different generic categories of functions between the ICUs of the first decade (1993-2002) and the second decade (2003-2012). The study also finds notable differences in space allocation among different generic categories of functions in relation to size, construction type, specialty type and layout type. Despite several limitations, the study should help design better adult ICUs based on an evidence-based understanding of the relationships between space allocation and strategic choices.
\end{abstract}

Key words: adult ICUs, space allocation, size, construction type, specialty type, layout type

Acknowledgement: The study was supported in part by the General Research Fund of the University of Kansas. The author would like to thank the anonymous reviewers for their comments. 


\section{Space Allocation in the Award-Winning Adult ICUs of the Last Two Decades (1993-2012): An Exploratory Study}

\section{INTRODUCTION}

Most construction projects include spaces serving different functions. The functional category of a space is generally defined based on the primary set activities that would occur in the space. Yet, a space of any one functional category may not exclude some secondary activities. For example, in an intensive care unit (ICU), a space would be put in the functional category of 'patient room' if the space would be occupied by a patient most of the time and if the activities there would mostly be related to patient care. However, it is quite possible that secondary activities not directly related to patient care, such as viewing TV, would also occur in a patient room. Similarly, a space would be put in the functional category of "nursing station' if the space would be occupied by nurses most of the time and if the activities there would mostly be performed by nurses. Again, this functional categorization may not prevent physicians from using a nursing station in ICUs. How strictly the functional categorization of spaces are put in practice often depend on the culture of an organization that uses the spaces.

The functional categorization of spaces is useful shorthand for describing and characterizing a construction project. Space allocation among different categories of functions (also known as programming) is important, because everyone involved in a construction project - project programmers, planners, design consultants, and clients - may need the information to determine precisely the scope of the project. Since the amount of human, financial, technology and systemic resources vary for different functions, the amount of space allocated to each of these functions can be a better indicator of these requirements than the more general metrics such as the gross square footage, net square footage, or the net-to-gross ratio. 


\section{[SPACE ALLOCATION AMONG DIFFERENT CATEGORIES OF FUNCTIONS IS}

\section{PARTICULARLY IMPORTANT FOR INTENSIVE CARE UNITS (ICUS), BECAUSE RESOURCES}

REQUIRED FOR DIFFERENT FUNCTIONS IN THESE UNITS VARY SIGNIFICANTLY.] Space allocation among different categories of functions is particularly important for ICUs, because resources required for different functions in these units vary significantly. Consider the technology requirements for the three generic categories of functions - patient care areas, support and service areas, and circulation areas - in ICUs. Generally, these requirements are very high for patient care areas in ICUs; moderate for support and service areas; and low for circulation areas. Even though there is no guarantee that such estimation would not vary from one case to another, it must be helpful to know how much space is generally given to each of these generic functions of an ICU to determine the overall technology requirements of the unit in the initial stages of design.

Along with space allocation among different categories of functions, the relationships among the amounts of space or area given to different categories of functions are also important for any construction project. When these relationships are predictable for a class of projects, the programming and planning of any project of the class become easier. Most programmers, planners, design consultants, and clients have their own methods or models for determining the amounts of space for different functions of their projects, but in most cases the knowledge has remained proprietary. This observation is also true for ICUs, despite the fact that the relationships among different categories of functions are quite strong in ICUs. In most ICUs, staff work areas cannot be separated from patient rooms for constant monitoring requirements of ICU patients. Similarly, having supply and support functions closer to patient rooms in ICUs may help reduce walking and improve efficiency. In many cases, having supply and support functions closer to patient rooms may also help reduce the risk of infection and injury. To help fulfill the requirements of strong functional dependencies, ICUs are often conceived as one or more somewhat self-sufficient pods; and it is often very hard to split an ICU or its pods and put them on adjacent floors or adjacent but non-contiguous spaces without some negative consequences. Therefore, studies on how the amount of space of any one 
category of function is related to that of another category in ICUs are needed. Without this knowledge, space allocation among different categories of functions in ICUs remains mostly an educated guesswork among programmers, planners, consultants, and clients.

Studies on space allocation among different categories of functions are needed not only because a knowledge gap exists, but also because many uncertainties exist in the process of designing a project. In general, the primary determinants of space allocation among different categories of functions are the needs of and relationships among people, objects (such as furniture and technology), and activities. Programmers, planners, design consultants, and clients are likely to consider these aspects while allocating space in the functional program of a project. However, it is not always possible to perfectly map all the functional needs into space allocation in the design of a project for different strategic reasons. The size of a construction project is such a strategic reason. Examples may include the number of beds in a hospital, the number of keys in a hotel, or the number of shops in a mall. The size of a project is not something that a designer often determines. It is given to her by the client, who determines the size of a project on the basis of the projected return on investment. As a result, it can become a strong force determining space allocation among different functions. Take the scenario where the client determines that a 20-bed ICU would be best for her organization based on the projected return on investment but there is only space available for an 18-bed unit. In this scenario, a designer may make patient rooms, support and service areas, and/or circulation areas a bit tighter to accommodate a 20-bed unit. Now imagine a converse scenario, where the client determines that an 18-bed would be the best for her organization based on the projected return on investment but there is room available for a 20-bed unit. In this scenario, the designer often uses of the extra space to make patient rooms, support and service areas, and/or circulation areas a bit larger; thereby, improving functional flow. When there is more or less space available than that required for the given size of a project, the designer looks at the existing trends to help make the decision. However, an ICU designer cannot do this because how unit size affects space 
allocation in ICUs is not known (cf. Allison \& Hamilton, 2008; Cadenhead \& Anderson, 2009; Hamilton \& Shepley, 2010; Rashid, 2006). Therefore, studies are needed in this area of ICU design.

The type of a construction project is another strategic reason for imperfect mappings between functional needs and space allocation. Examples of project construction types may include new construction, renovation, and part-new and part-renovation projects. For a new construction project, it is relatively easy to allocate space based on the functional program of the project. However, it is not easy to allocate space based on the functional program in a renovation projects. Again, let us consider ICUs in relation to construction types. Most ICUs are generally located in urban hospitals. Therefore, it often makes more sense in terms of economy and convenience to renovate or upgrade an existing ICU than to build a new one (cf. Bartley, Olmsted, \& Haas, 2010; Rashid, 2006). This often creates challenges for an ICU designer in terms of his/her ability to work around the limitations posed by an existing structure. Any old hospital facility can pose several design limitations for an ICU in terms of function, structure, dimension, environmental systems and utilities. Many hospitals of the 1960s and 1970s were built with 8' floor to ceiling height, 11'-6" floor to floor height, 20" structural depth, and/or less than 20" clear ceiling plenum. These are difficult limitations, and they are likely to affect space allocation among different functions in ICUs. Since an ICU designer is responsible for ensuring the overall efficiency and effectiveness of an ICU even under extremely limiting physical conditions, studies are needed to understand how space allocation is affected by construction types to help her make the right choices.

The type of functions and activities being considered is yet another strategic reason for imperfect mappings between functional needs and space allocation. Not all functions and activities follow predictable patterns. Some environments such as shopping malls thrive on unpredictability, while others such as prisons want to eliminate it. Even within the same environments, multiple smaller units or settings may co-exist with different functional and activity patterns. Hospitals are good examples of such complex settings, where no one department is similar to another in terms of people, objects (such as furniture and technology), and activities. It is often a matter of strategic choice whether unpredictability in functional 
and activity patterns ought to be encouraged or not in an environment. Physical design can help improve the overall efficiency and effectiveness of a project by imposing different amount of restrictions on movement, interface and interaction among people, objects (such as furniture and technology), and activities. This observation is important for ICUs, because the needs of and relationships among people (patient, staff, and visitors), objects (such as furniture and technology), and activities are very different in different types of ICUs. Therefore, there is a need to study how space allocation in ICUs varies by functional types or specialty.

Layout typology, such as the racetrack layout, open-plan layout, cellular layout, single or double corridor layout, perimeter corridor layout, and the courtyard layout, can also affect space allocation in a project by imposing limitations and advantages. For example, a racetrack layout may provide more perimeter walls, but may also include a central core with little or no access to natural light and outside view. An open-plan layout may enhance visibility and interaction among spaces and people, but may reduce privacy. A cellular type layout may enhance privacy, but may reduce visibility. A courtyard layout may allow natural light and outdoor view for interior spaces around the courtyard, but may need more space to do so. In the early stages of design, designers use layout typology as a heuristic tool to organize functions and spaces. That is because designers want to understand the limitations and advantages of each layout type before they select a layout that meets the programmatic requirements sufficiently. Therefore, the relationships between layout typology and space allocation must be important for all construction projects including ICUs.

Based on the observations made above, this study involving adult ICUs was conducted to describe space allocation of among different categories of functions in these ICUs, and to determine how the amount of space of any one category of function might be related to that of another category in these ICUs. It was also conducted to determine how different strategic choices, such as unit size, construction type, unit specialty and layout type, might affect space allocation in adult ICUs. These are important issues in light of the fact that even though critical care practice has already undergone significant changes in the last few 
decades, it is still an evolving domain of medical practice. As a result, ICU design is also evolving as new regulatory standards, new technologies, and new clinical models are being introduced. A good understanding of the above issues regarding space allocation may help us better guide the evolution of ICU design.

\section{LITERATURE REVIEW}

Space allocation in ICUs is a poorly researched topic with very little published studies (examples, Allison \& Hamilton, 2008; Cadenhead \& Anderson, 2009; Hamilton \& Shepley, 2010). Allison \& Hamilton (2008) reported the gross square footage, net (usable) square footage, and the "net-to-gross ratio" or the grossing factor of a set of 19 ICUs in the United States, designed by some of the better healthcare design firms of the country. This is an important study in relation to space allocation, because programmer, planners and consultants use the grossing factor to determine the total area of a proposed project based on the net square feet required for the programmed, usable spaces. In other words, the grossing factor helps estimate the amount of space required but not included in the net square feet of the programmed spaces of a project. These un-programmed spaces along with the programmed spaces determine the gross area of the project, which then forms the basis for the project budget. To help other researchers in the field, Allison \& Hamilton (2008) also included a review of the relevant area calculation methods found in the literature, and defined "protocols for conducting the area takeoffs, given the lack of published and industry accepted standards for determining net $[\mathrm{NSF}]$ and particularly departmental gross square feet [DGSF]" (2008:6).

Based on their study of 19 ICUs, Allison \& Hamilton (2008) reported that the minimum grossing factor for these ICUs was 1.34, the maximum 1.96, the range 0.72, and the mean was 1.56 (STD 0.15). The study also reported a wide range in the grossing factors of different layout types. Their findings, therefore, lend some support to an earlier observation made here that layout types could be a determining factor for 
space allocation among ICUs. Though the more specific findings on the grossing factors of the study are less relevant to the present study, the definitions and/or protocols for conducting the area takeoffs of the study are. They are used in the present study; and were used in another previous study of space allocation in ICUs reported by Cadenhead \& Anderson (2009). Cadenhead \& Anderson (2009) is more relevant to the present study for it described, among other things, space allocation among different categories of functions in a set of award-winning adult ICUs.

Recognizing the importance of ICU design, since 1992 the Society of Critical Care Medicine (SCCM), the American Association of Critical Care Nurses (AACCN), and the American Institute of Architects/Academy of Architecture for Health (AIA/AAH) have been co-sponsoring an annual ICU design competition. The competition recognizes ICUs that make exceptional efforts to promote healing of the critically ill and injured patients through the design of the critical care unit environment. Since its inception, the competition has been open to all ICUs regardless of medical specialty or subspecialty. Each year, several geographically-dispersed groups of ICU design experts evaluate the competition entries for the award/s. For evaluation purposes, the group members use a standard form that includes numerical scores for such overall design features as size, layout, functionality, safety, security, and technology; and such individual design features as noise, light, color, materials, and amenities. (For more on the competition process, see Cadenhead and Anderson, 2009.)

Since the winning entries of the SCCM, AACCN, \& AIA/AAH competition represent some of the bestpractice example ICUs, Cadenhead and Anderson (2009) studied space allocation in 12 of these awardwinning adult ICUs. Like the Allison \& Hamilton (2008) study, Cadenhead and Anderson (2009) studied the grossing factors of these ICUs; and found that these factors were different for different types of construction. For new construction, the mean grossing factor was 1.57; for mixed construction (new and renovation), it was 1.65; and for renovation, it was 1.69. Their findings, therefore, lend some support to another earlier observation made above that construction types could be a determining factor for space allocation among ICUs. 
Cadenhead and Anderson (2009) also reported space allocation among different categories functions in the award-winning ICUs. The functional categories they studied were patient care, staff and material support, staff facilities, diagnostic and therapeutic, administration and education, and public and family. They made the following observations: 1) Patient care areas, which included "the patient room and toilet," used $48 \%$ of the unit gross area; 2) staff and material support areas, which included "centralized and decentralized nurse stations, clean and soiled utility, etc.," used 23\% of the unit gross area; 3 ) staff facilities, which included "staff lounge, lockers, toilets, on-call rooms, etc.," used $6 \%$ of the unit gross area; 4) diagnostic and therapeutic, which included "imaging suites, dialysis, pharmacy, lab, etc.," used $2 \%$ of the unit gross area; 5) administration and education, which included "classrooms, conference rooms, offices, etc.," used 9.0\% of the unit gross area; and 5) finally, public and family areas, which included "waiting areas, family sleep rooms, amenities, etc.," used $12 \%$ of the unit gross area in these award-winning ICUs. Though these observations are relevant to the present study, Cadenhead and Anderson (2009) made no observations on several important issues identified earlier regarding space allocation in ICUs. Therefore, this study on space allocation in adult ICUs was undertaken.

\section{MATERIALS AND METHODS}

Like the Cadenhead and Anderson (2009) study, this study was based on a systematic content analysis of the materials submitted to the SCCM, AACCN, \& AIA/AAH competition by the winning ICUs of the last two decades from 1993 to 2012. For competition purposes, all entries submitted a fact sheet with the background information that included, among other things, the type and size of the hospital that houses the unit, the type and size of the unit, the type of design, the size of a typical patient room, the type of power/equipment mounting in the patient room, the date of completion and occupation, the type of construction, and the budget. All entries also submitted a video footage with audio narrative, a brief written description, and one or more drawings of the floor plan and the building block plan. These 
materials were jointly published in a CD and a DVD by SCCM, AACCN, and AIA/AAH in 2012 (SCCM, AACCN, \& AIA/AAH, 2012).

A few of the award-winning adult ICUs were excluded from the study, because the published materials did not contain legible drawings with adequate labeling and design information. All the award-winning neonatal and pediatric ICUs were also excluded from the study. Additionally, one award-winning adult ICU from the Netherlands was also excluded from the study, because it had several design features not commonly found in this country. Altogether, the study included 25 award-winning adult ICUs built between 1993 and 2012. Out of the 25 ICUs, 15 ICUs represented the decade from 1993 to 2002 and 10 ICUs the decade from 2003 to 2012. In addition to the exclusion criteria above, these unequal numbers can also be explained by the fact that the numbers of winning ICUs in a year were sometimes more than one, and that some of the winning entries were not always adult ICUs (SCCM, AACCN, \& AIA/AAH, 2012). The study was limited to the three generic functional categories- patient care areas, support and service areas, and circulation areas - because many drawings in the 2012 SCCM, AACCN, \& AIA/AAH publications were not labeled adequately to allow for a more robust space allocation study. By focusing on a set of generic functional categories, the study was able to reduce the number of arbitrary decisions.

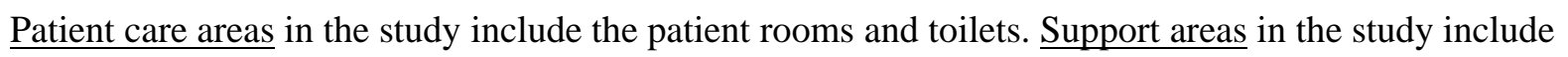
designated spaces or areas in which staff members perform auxiliary functions related to patient care. The basic component of support areas include staff work areas composed of centralized nurse station, substations, observation stations, and/or charting area. Other support areas are administrative offices, conference spaces, on-call rooms, staff lounge, restrooms and lockers; and pharmacy, laboratory, and imaging when available. Additionally, support areas in this study also include areas that provided support for patient families and visitors. These spaces include, but are not limited to, family waiting area or lounge, consultation rooms, family nourishment space, sleeping rooms, meditation spaces, and spaces with such amenities as lockers, washer and dryers, and bathrooms with shower. Service areas in the study include clean utility room, soiled utility room, patient nourishment space, med supply room, 
housekeeping, and any other storage spaces. Circulation areas in the study include internal hallways, corridors, and/or aisles used by all ICU users - patients, ICU staff, and visitors. They do not include private movement areas within any well-defined areas such as the nursing station and the patient room. They also do not include elevator cores, fire-stairs, and open lobby areas if identified as waiting spaces.

Different categories of unit construction types included in the study were new construction, renovation, and part-new and part-renovation. Two categories of unit specialty types included in the study were single- and mixed-specialty or -subspecialty. Different categories of unit layout types included in the study were racetrack type, single-corridor type, open-plan type, radial type, and other (some combination or modification of the former types).

The data for the study were collected from the drawings and the other materials submitted by the winning entries (SCCM, AACCN, \& AIA/AAH, 2012). The data included the year of award, the gross area of the unit, the areas of different generic functions, the size of unit or unit beds, the type of construction, the specialty of unit, and the type of layout. For the data on areas, the floor layout of each ICU included in the publications was scaled appropriately. Using the floor layout as an underlay, the unit gross area and each of the three generic areas - patient care areas, support and service areas, and circulation areas - were identified as shapes in AutoCAD. The areas of the shapes were then calculated to determine approximate space allocation. Once all the data were collected, IBM SSPS Statistics 20 (IBM, 2011) was used for statistical analyses. The analyses included both descriptive and correlational statistics. The findings of the analyses are reported below along with evidence-based discussions underscoring the importance of topics included in the study.

\section{UNIT SIZE \& SPACE ALLOCATION}

The size of an ICU must be appropriate for constant visibility between ICU patients and care providers. It must also be appropriate for care providers to become fully aware of all the people, not just the patients, 
and activities on the floor. Additionally, the size must also be appropriate for less walking and noise. Smaller units that fulfill these needs better, however, may not permit efficient staffing. Smaller units may not also justify having a procedure room, a satellite lab, a radiologic unit, a satellite pharmacy, an appropriately sized family waiting space or a staff lounge; thus, affecting safety, efficiency, family integration, and staff comfort and satisfaction (cf. Hamilton \& Shepley, 2010).

Literature suggests maximum eight to 12 beds per unit for better observation (Hamilton, 1999, 2000; NIH, 1983). In general, larger ICUs with more beds have more infections (for example, see Archibald et al., 1997; Borg, 2003; Vincent, Bihari, Suter, et al., 1995). Therefore, when units have more than 12 beds they can be divided into clusters or pods of six to eight to permit efficiency and economy. Staffing models should be considered in determining the size and clustering of a unit. For example, for a 2:1 staffing model ( 2 patients for 1 nurse) it is better to have even numbers of beds in an ICU or in the clusters of an ICU. For this reason, units with 12, 16, and 20 beds may work better. A 24-bed unit can have two 12-bed pods, but these large pods may not be optimal for efficiency and economy. A 24-units can also have an asymmetrical layout with three pods of 8-bed, where it may be difficult to find optimal locations for support and service functions in relation to patient rooms.

This study shows that the average number of patient beds was 20.67for the 1993-2002 adult ICUs, whereas it was 26.6 for the 2003-2012 adult ICUs. In other words, the 2003-2012 adult ICUs were bigger than the 1993-2002 adult ICUs almost by six beds or 29\% (Figure 1). The average for all the units was 23.63, which is also a much higher number than the numbers recommended by the SCCM Guidelines (1995, 2012) and by ICU experts (Hamilton, 2000; NIH, 1983). Since neither an operational-functional perspective nor a socio-ecological perspective can fully justify very large ICUs even when these units are broken down into smaller pods (Rashid, 2006), studies are needed to understand why the award-winning ICUs have such a high number of patient beds. 


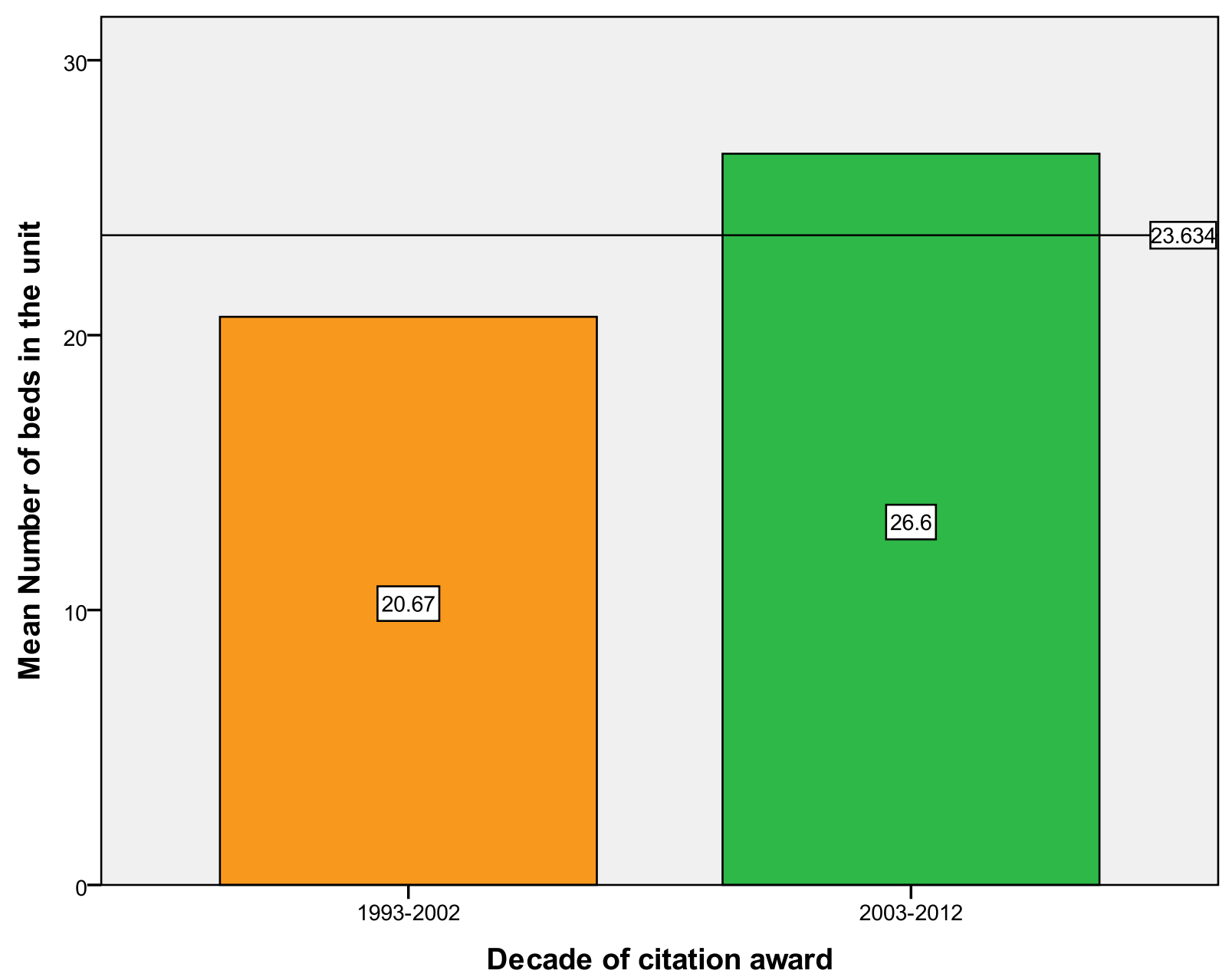

Figure 1: Mean number of unit beds by decade.

\section{[EVEN THOUGH THE NUMBER OF PATIENT BEDS INCREASED BY 29\% IN THE SECOND}

\section{DECADE, THE MEAN OF THE APPROXIMATE GROSS AREA PER PATIENT BED DECREASED}

FROM 883 SQUARE FEET PER BED IN THE 1993-2002 ICUS TO 855.9 SQUARE FEET PER BED

IN THE 2003-2012 ICUS.] Even though the number of patient beds increased notably in the second decade, the mean of the approximate gross area per patient bed decreased from 883 square feet per bed in the 1993-2002 ICUs to 855.9 square feet per bed in the 2003-2012 ICUs. Since the mean for all the ICUs in the sample was 869.41 square feet per bed (Figure 2), it would seem that the design of award-winning ICUs became more efficient in terms of space allocation in the second decade. This, in itself, was a significant progress since space can be a very expensive resource in hospitals for many reasons. 
A more remarkable difference in terms of space allocation between the 1993-2002 and 2003-2012 ICUs, however, is that the mean of the total patient room area as percentage of the unit gross area increased from $30.31 \%$ in the first decade to $36 \%$ in the second decade (Figure 3A). In other words, more space was given to patient rooms in the second decade. This is a positive development since more space in the patient room often translates into more flexibility in terms of patient care.

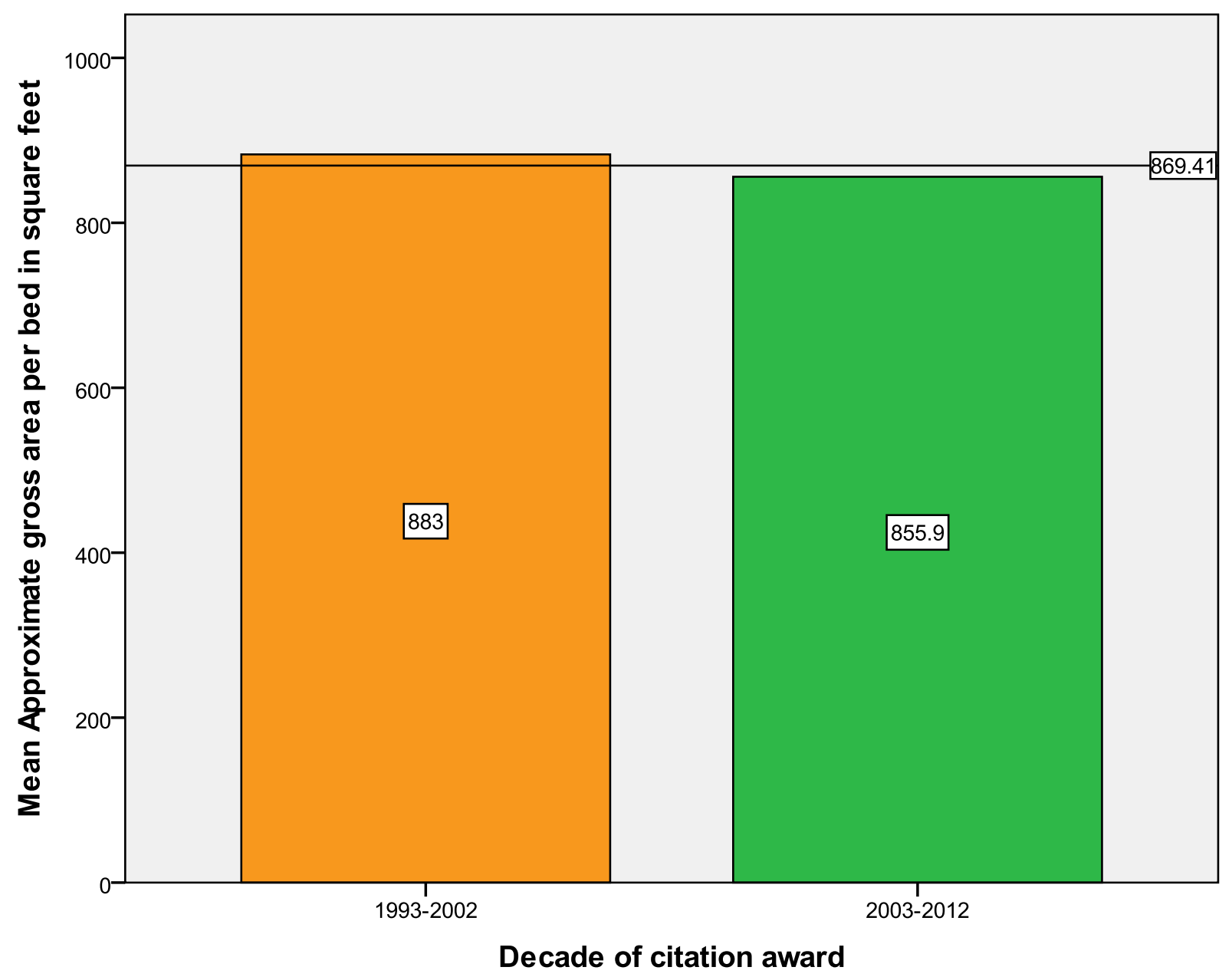

Figure 2: Mean approximate gross area per bed by decade. 

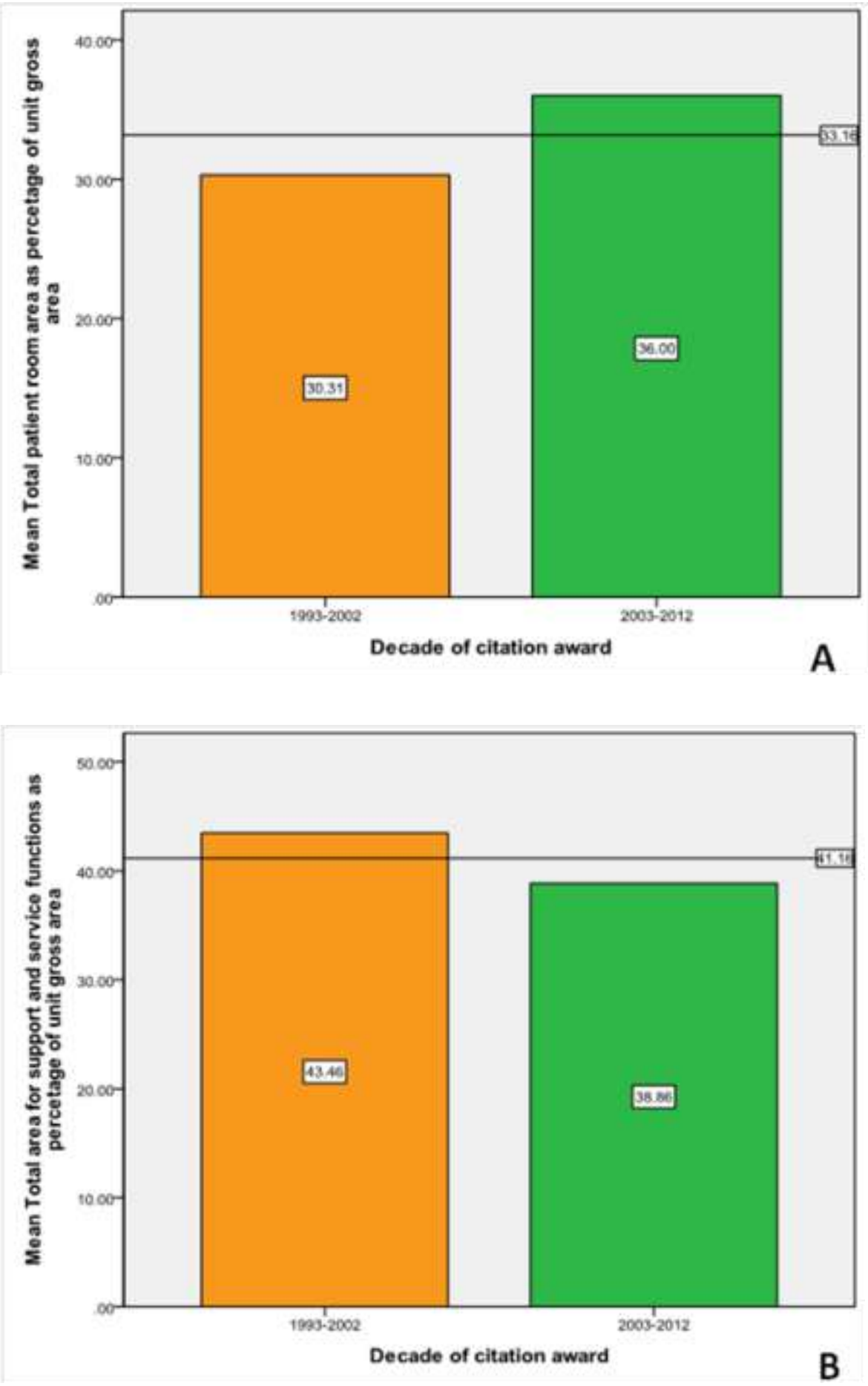


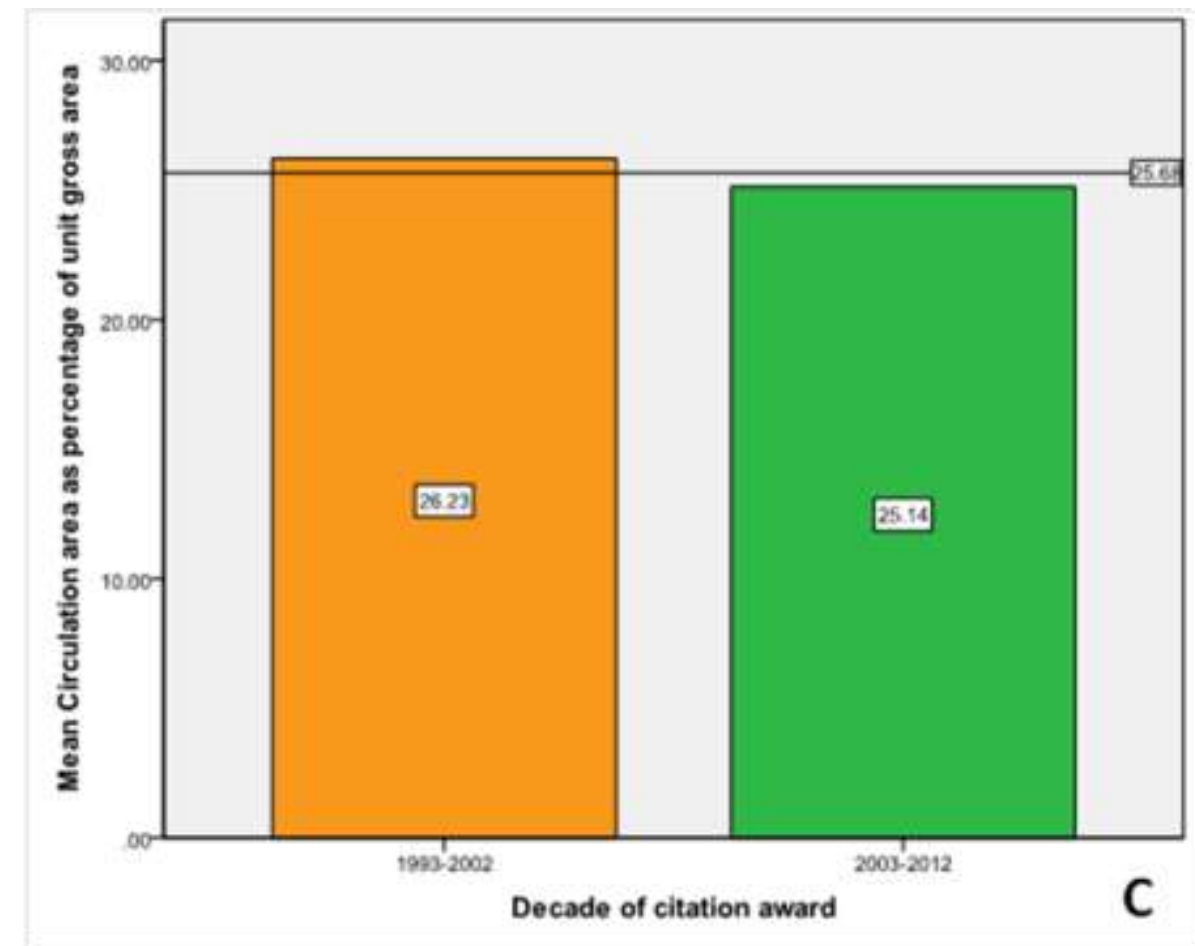

Figure 3: Allocation of space by decade. A) Mean total patient room area as percentage of unit gross area. B) Mean total area for support and service functions as percentage of unit gross area. C) Mean total circulation area as percentage of unit gross area.

Since the mean approximate gross area per patient bed increased in the 2003-2012 ICUs, the excess space for patient rooms was acquired by reducing circulation, support, and service areas in these ICUs. The mean of support and service areas as percentage of unit gross area decreased from $43.46 \%$ in the first decade to $38.86 \%$ in the second decade (Figure 3B); and the mean of circulation areas as percentage of the unit gross area decreased from $26.23 \%$ in the first decade to $25.14 \%$ in the second decade (Figure 3C). These findings provide additional evidence supporting the fact that the design of award-winning ICUs might have become more efficient in terms of space in the second decade because they were using less support, service and circulation areas. This finding that the patient room is getting bigger while the other spaces are getting smaller in ICUs make sense in light of the fact that the number of older and more acutely ill patients in ICUs is rising. These older and more acutely ill patients stay longer in ICUs and require more point of care services for improved safety. In this regard, a larger patient room is better for 
several reasons. First, it supports more point of care services. Second, it enhances safety by keeping nurses at the bedside. Finally, it helps improve patient and family satisfaction by providing more family space.

\section{CONSTRUCTION TYPE \& SPACE ALLOCATION}

Changes in technology, patient demographics or disease patterns, performance standards, and care delivery models are among the important reasons for building new ICUs or renovating the old ones. Building new ICUs may be costlier but renovating the old ones is never easy, as was noted earlier. Renovations often put patients and staff in harm's way that can be avoided in a new construction. In the absence of appropriate protection provisions, renovations may cause disruption in patient care and building services. They may expose patients and staff to disruptive noise, harmful allergens, and carcinogenic materials (particularly when hospital facilities are old enough to contain asbestos). During renovation, vulnerable patients are often moved to temporary locations that lack optimal care environments. (For examples of studies on safety and construction in hospitals see Bartley, Olmsted, \&Haas, 2010; Carter \& Barr, 1997; Goodley, Clayton, \&Hay, 1994; Iwen, Davis, Reed, et al., 1994; Oren et al., 2001.)

Recognizing many negative issues related to renovation, the FGI Guidelines states:

Renovation of a unit shall include phasing to minimize disruption of existing patient services. Phasing plans shall include considerations of noise and vibration control that result from construction activities. During construction renovation areas shall also be isolated from occupied areas based on infection control risk assessment (ICRA). Existing air quality requirements and other utility requirements for occupied areas (for example, domestic water, treated water, wastewater, pneumatic tube, pneumatic controls, and medical gases/vacuum) shall be maintained during any renovation. (FGI, 2010:32) 
The findings of the study show that [BETWEEN 1993 AND 2002 RENOVATION WAS MORE FREQUENT THAN NEW CONSTRUCTION, WHEREAS BETWEEN 2003 AND 2012 NEW CONSTRUCTION WAS MORE FREQUENT THAN RENOVATION AMONG THE AWARD-

WINNING ICUS] between 1993 and 2002 renovation was more frequent than new construction, whereas between 2003 and 2012 new construction was more frequent than renovation among the award-winning ICUs. Among the 1993-2002 ICUs, 46.67\% were the renovated units, 40\% were the newly built units, and $13.33 \%$ were the part-renovated and part-new units. In contrast, among the 2003-2012 ICUs $40 \%$ were the renovated units, $60 \%$ were the newly built units, and $0 \%$ was the part-renovated and part-new units (Figure 4).

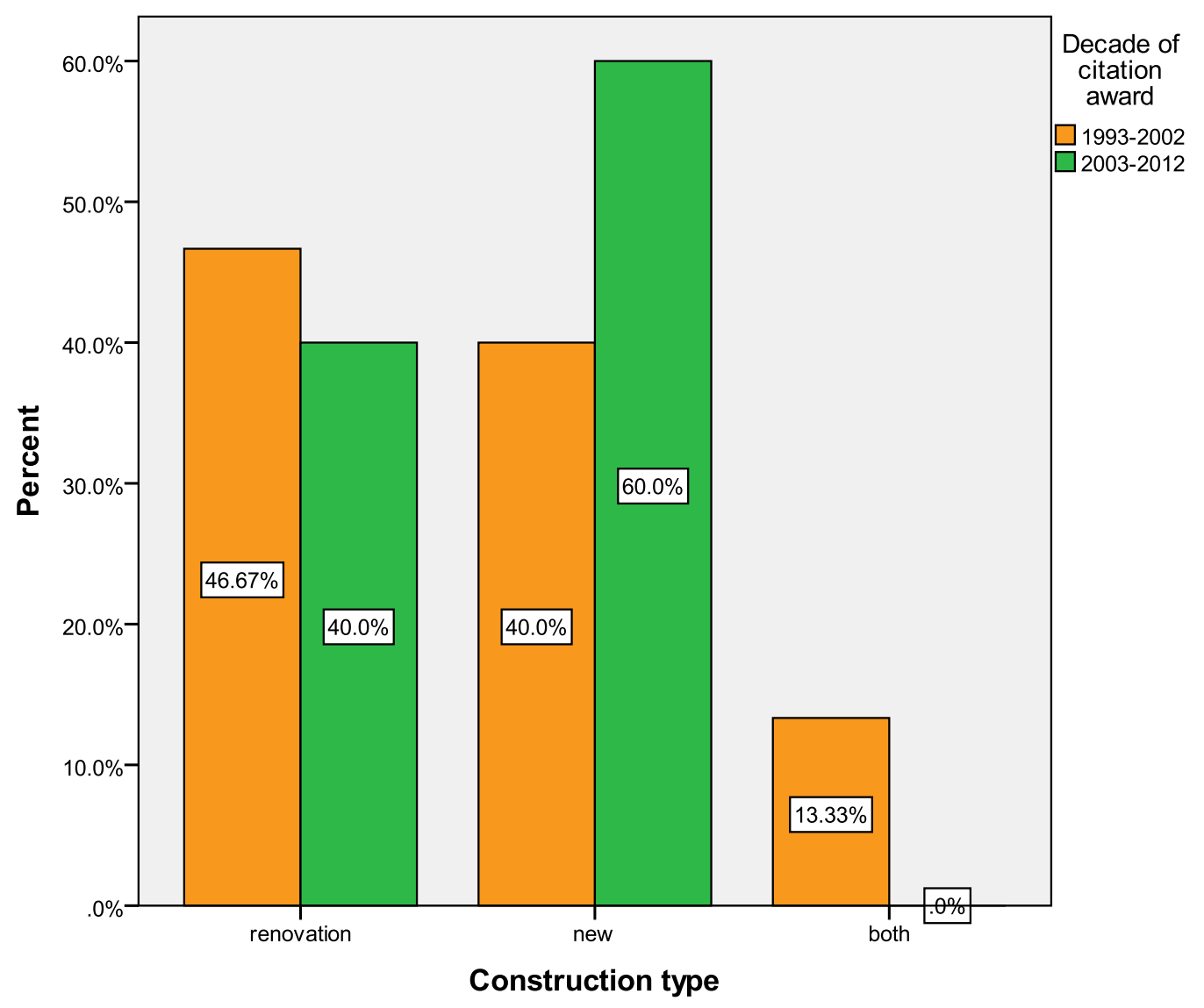

Figure 4: Different types of construction by decade. 
Therefore, the findings of the study indicate a positive trend among the award-winning ICUs since renovating ICUs can often become more hazardous and difficult than building new ICUs. It is hard to say if the findings were a mere coincidence. It is quite possible that in some of the years no new construction or renovation entries were submitted. Nonetheless, it would be interesting if the findings indicate a more general trend in ICU construction. It would also be interesting if the findings indicate an increasing awareness regarding the safety issues associated with ICU construction around the country.

Based on construction type, the overall space allocation as represented by the mean of the approximate gross area per patient bed was different in the units of the last two decades. The mean of the approximate gross area per patient bed was 885.7 square feet for the renovated units; 893.2 for the new units; and it was 671.1 square feet for the partly-renovated and partly-new units (Figure 5). The mean for the sample as a whole was 816.67 square feet. In other words, in terms of gross area per bed the new and the renovated units were comparable and above the average. In contrast, the part-renovated and part-new units were remarkably below the average.

Space allocation among different generic categories of functions - patient room area, support and service area, and circulation area - in these units were also different for different construction types (Figures 6A, B, \& C). For the renovated units, the means of the total patient room area and the total circulation area as percentages of unit gross area $(30.92 \%$ and $23.55 \%$, respectively) were below the means of the sample (34\% and $25.14 \%$, respectively), because the mean of the total support and service areas as percentage of unit gross area (45.53\%) was above the mean of the sample (40.82\%). For the new units, the means of the total patient room area and the total support and service areas as percentages of unit gross area (33.22\% and $38.58 \%$, respectively) were below the means of the sample ( $34 \%$ and $40.82 \%$, respectively), because the mean of the circulation area as percentage of unit gross area in these units $(28.21 \%)$ was above the mean of the sample $(25.14 \%)$. For the part-renovated and part-new units, the means of the total patient room area as percentage of unit gross area $(37.98 \%)$ was above the mean of the sample (34\%), because 
the means of the total support and service areas and the total circulation area as percentages of unit gross area $(38.37 \%$ and $23.66 \%$, respectively) were below the means of the sample $(40.82 \%$ and $25.41 \%)$.

The observed differences in space allocation among different generic categories of functions in different construction types might have been the result of different strategic choices that were made in the process of design. While for the renovated units and the part-renovated and part-new units some of these choices might have been determined by the already existing constraints, in the case of the new units there were less of the existing constraints. Therefore, the strategic choice to provide generous circulation spaces with otherwise adequate patient rooms and support and service areas that met the standards of best-practice in the new ICUs could have been motivated by the recent studies that showed generous circulation space could provide additional opportunities for interaction and communication (example, Carthey, 2008).

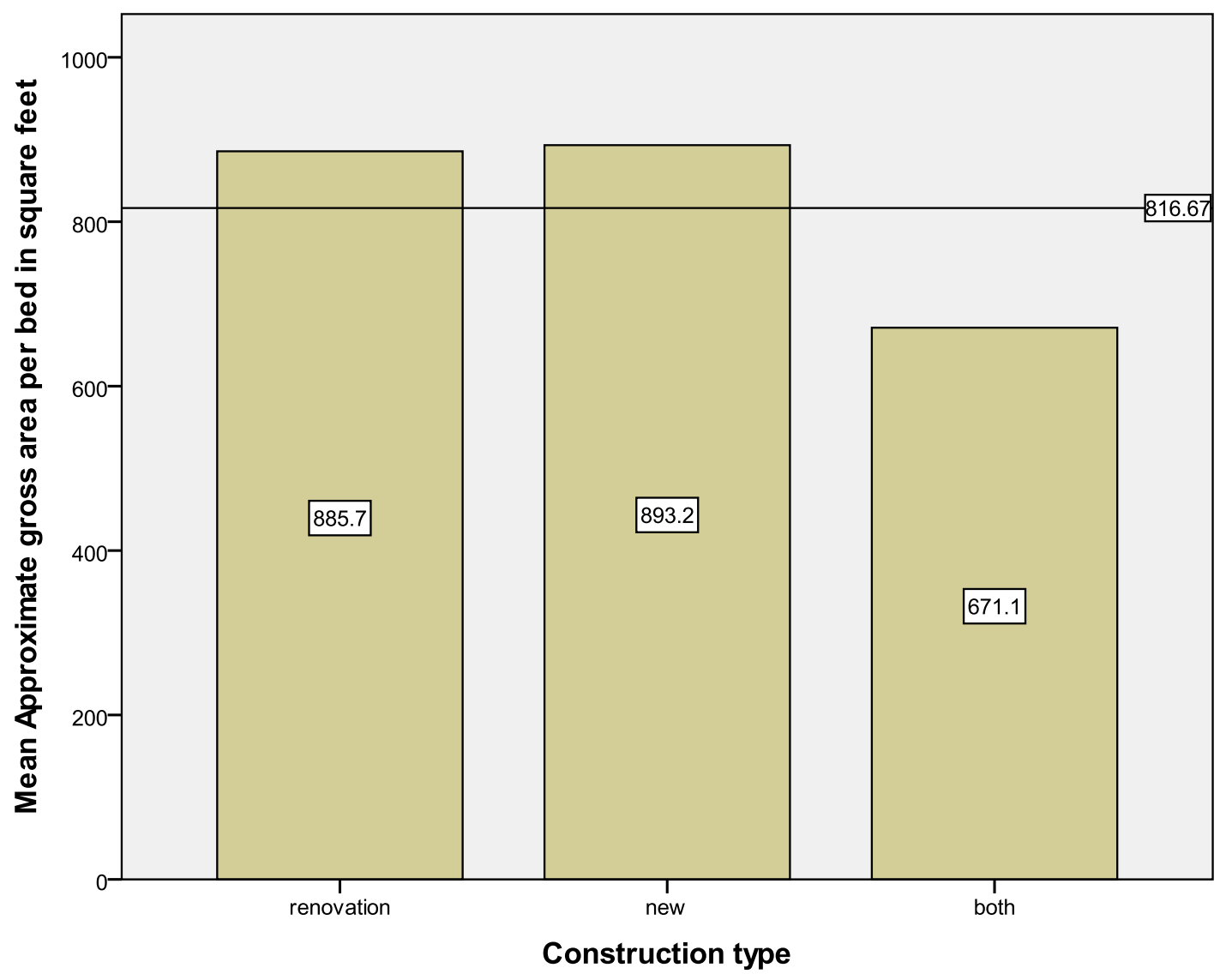


Figure 5: Mean approximate gross area per bed by construction type.
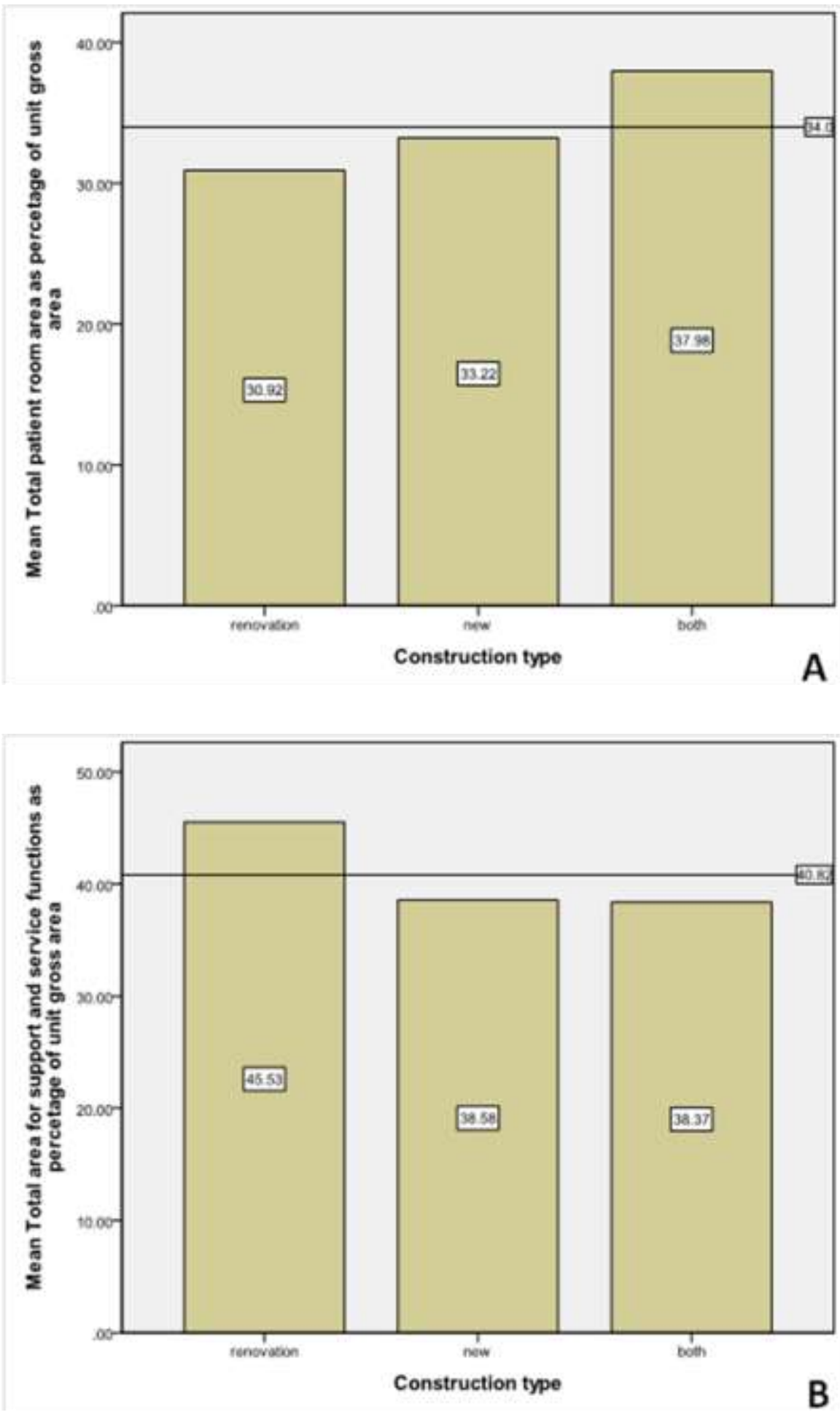


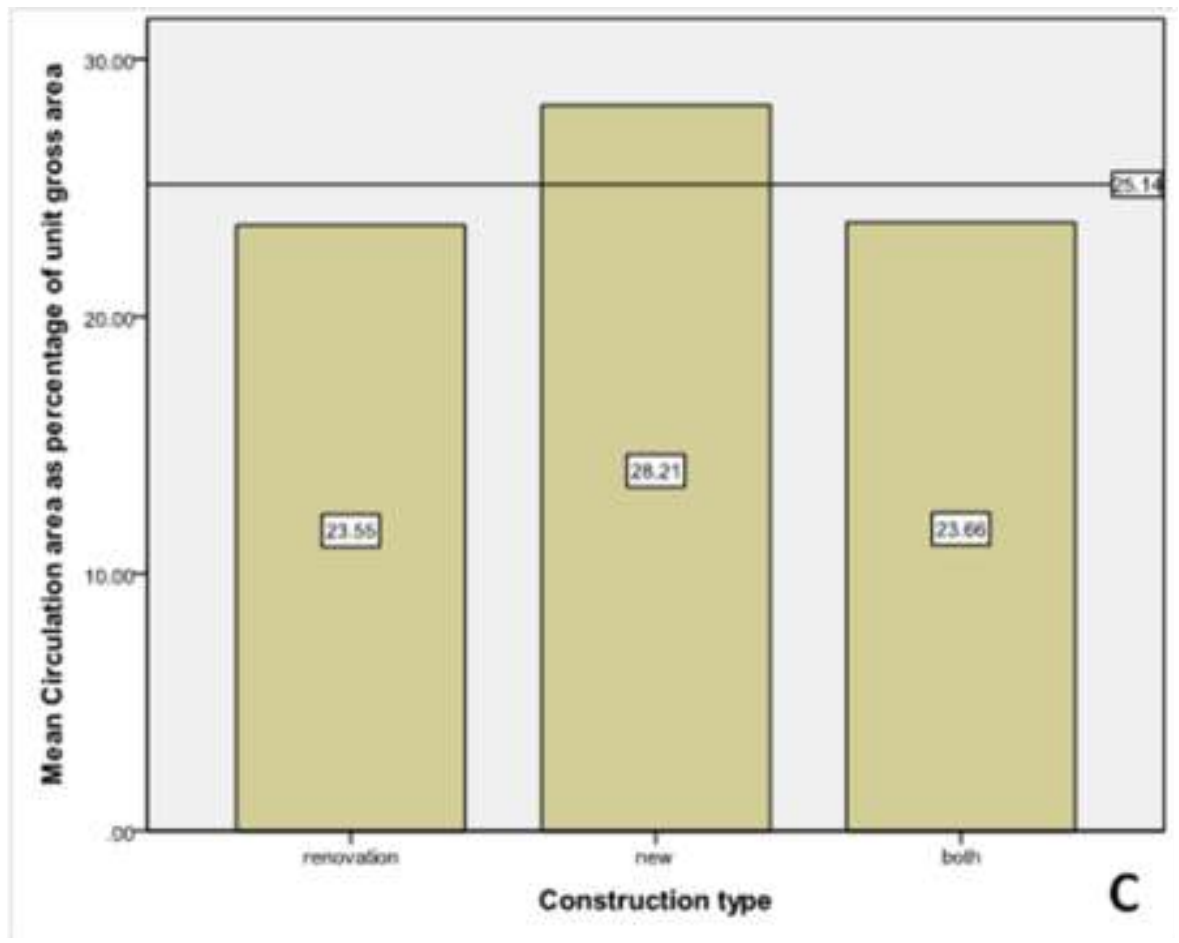

Figure 6: Allocation of space by construction type. A) Mean total patient room area as percentage of unit gross area. B) Mean total area for support and service functions as percentage of unit gross area. C) Mean total circulation area as percentage of unit gross area.

\section{UNIT SPECIALTY TYPE \& SPACE ALLOCATION}

Since types and severity of illnesses vary significantly among patients, no one critical care environment can support optimal care for all patients. Some patients are more unstable than others, thus requiring more monitoring. Some patients need more interventions than others, thus requiring more equipment and facilities for these interventions in the unit or in the patient room. Some patients stay longer than others, thus requiring more family spaces. Some patients are heavier than others, thus requiring more space and people for care. Some patients are more infectious than others, thus requiring more environmental protection. The list is almost without end. Therefore, there is a need for specialty or subspecialty ICUs that serve similar patients to the extent possible. Examples of these ICUs may include, but not limited to, 
Burn Intensive Care Unit, Coronary Care Unit (CCU), Cardiac Intensive Care Unit (CICU), Medical Intensive Care Unit (MICU), Neonatal Intensive Care Unit (NICU), Neurological Intensive Care Unit (Neuro-ICU), Respiratory Intensive Care Unit, Surgical Intensive Care Unit (SICU), and Transplant Intensive Care Unit (TICU). In addition to these specialty and/or subspecialty ICUs, mixed-specialty ICUs providing care for different types of illnesses are also available. However, in mixed-specialty ICUs managing and staffing patients are often difficult. They also have too many or too few features for some patients. Therefore, single-specialty or -subspecialty ICUs make more sense in terms of safety, efficiency, and effectiveness of critical care, when resources are available in the hospital to support these units.

Among the 1993-2002 ICUs 40\% were the single-specialty units and $60 \%$ were the mixed-specialty units. In contrast, among the 2003-2012 60\% were the single-specialty units and $40 \%$ were the mixedspecialty units (Figure 7). These findings indicate that [IN THE FIRST DECADE MORE UNITS SERVED MIXED-SPECIALTY THAN SINGLE-SPECIALTY, WHEREAS IN THE SECOND DECADE MORE UNITS SERVED SINGLE-SPECIALTY THAN MIXED-SPECIALTY] in the first decade more units served mixed-specialty than single-specialty, whereas in the second decade more units served single-specialty than mixed-specialty. Again, the findings may indicate a positive trend among the award-winning ICUs in light of the observation that a mixed-specialty unit may be more difficult to manage and staff than a single-specialty unit (for example, see Shortell, Zimmerman, Rousseau, et al., 1994).

The study finds that the mean of the approximate gross area per patient bed for the single-specialty units was less than the mixed-specialty units -865.3 square feet for the single specialty units vs. 878.4 square feet for the mixed specialty units (Figure 8). A difference of 13.1 square feet per bed between the singleand mixed-specialty type ICUs may not look so big, but this difference may translate into a significant dollar amount when the units have as many as 40 beds. 
Based on specialty type, space allocation among different generic categories of functions - patient room area, support and service area, and circulation area - in these units were different (Figures 9A, B, \& C). For the single specialty units, the mean of the total patient room area as percentage of unit gross area (36.17\%) was above the mean of the sample (32.73\%), because the means of the total support and service areas and the total circulation area as percentages of unit gross area (39.35\% and $24.48 \%$, respectively) were below the means of the sample $(41.53 \%$ and $25.74 \%)$. For the mixed specialty units, the means of the total patient room area as percentage of unit gross area $(29.28 \%)$ was below the mean of the sample $(32.73 \%)$, because the means of the total support and service areas and the total circulation area as percentages of unit gross area $(43.71 \%$ and $27 \%$, respectively) were above the means of the sample $(41.53 \%$ and $25.74 \%)$. These findings indicate that in the mixed-specialty units a greater need for more circulation, support, and service areas was met by reducing the area for patient rooms. In contrast, patient rooms in single-specialty units could be made bigger because they probably did not need as much circulation, support, and service areas as the mixed-specialty units. 


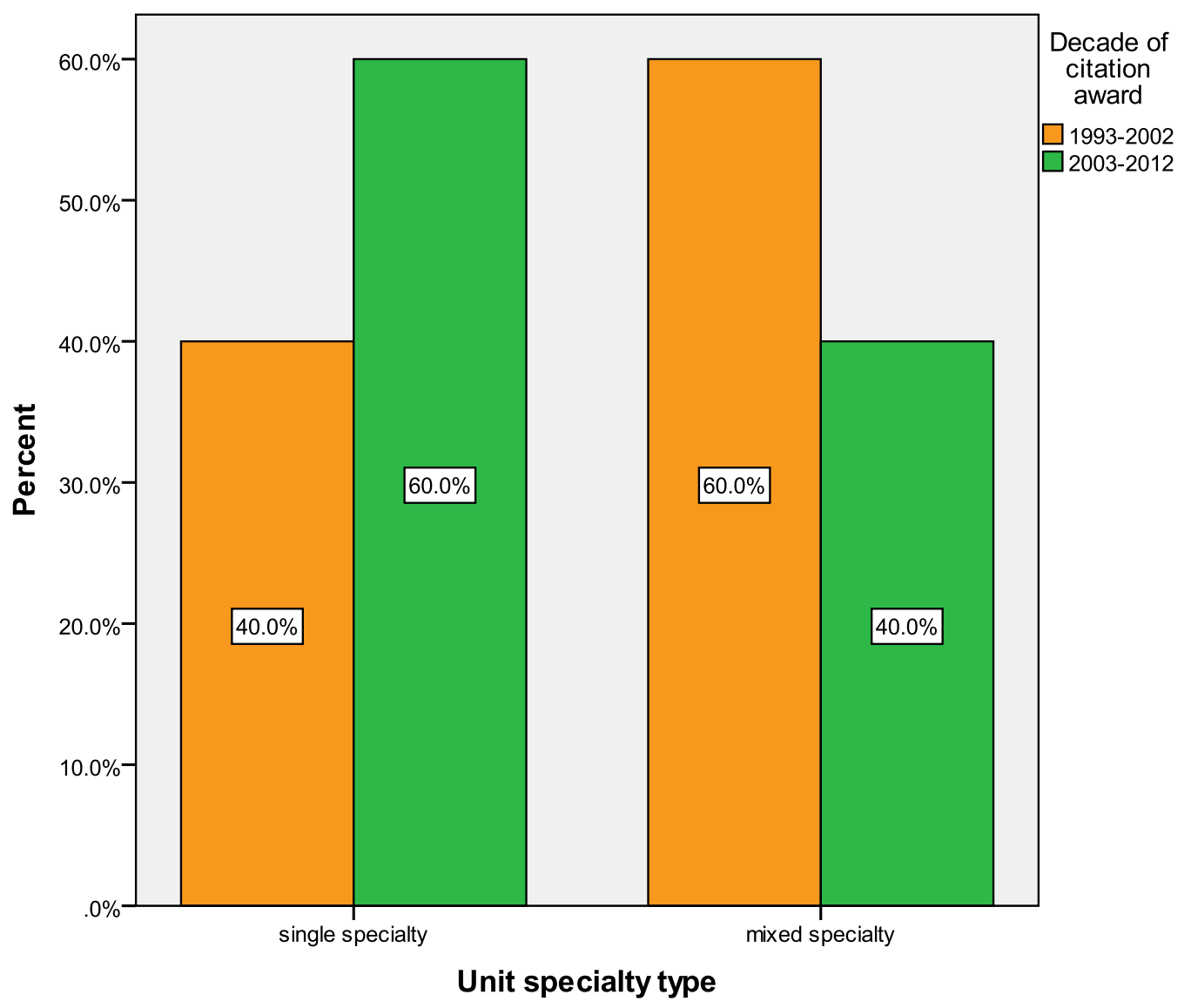

Figure 7: Single- and mixed-specialty ICUs by decade.

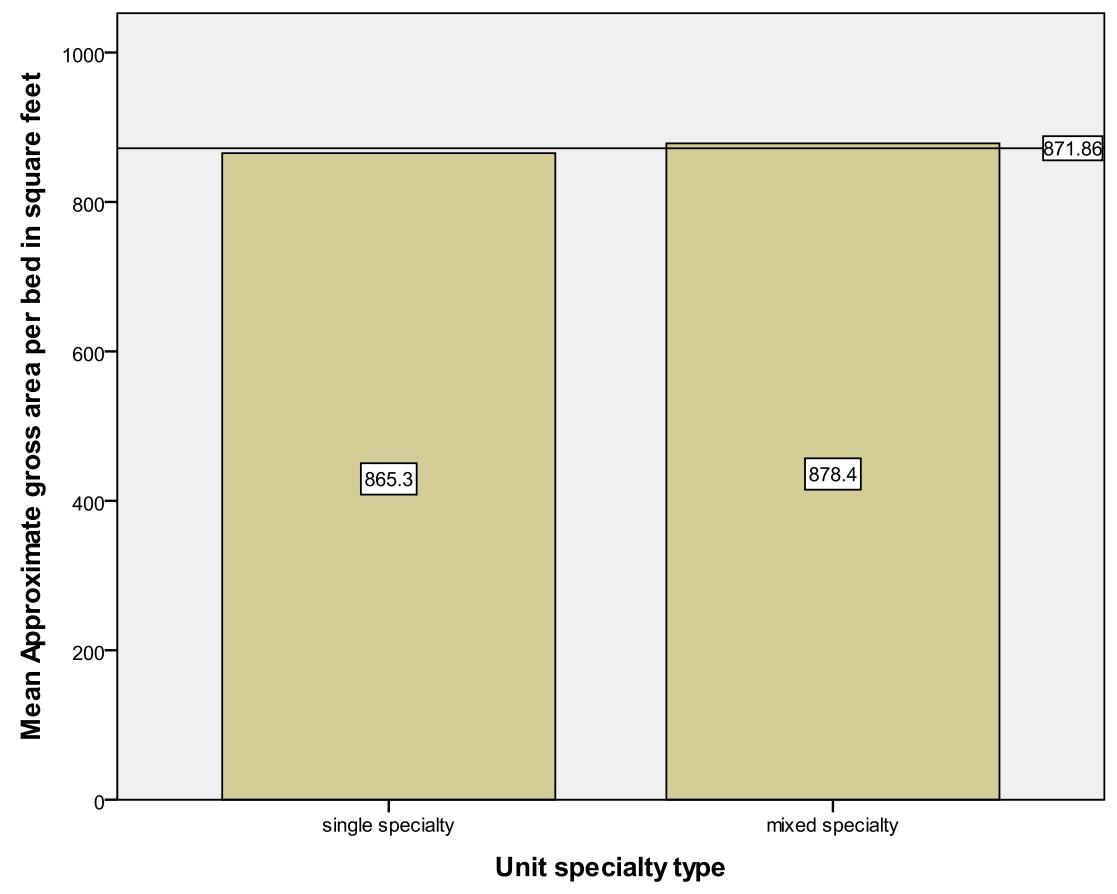


Figure 8: Mean approximate gross area per bed by unit specialty type.
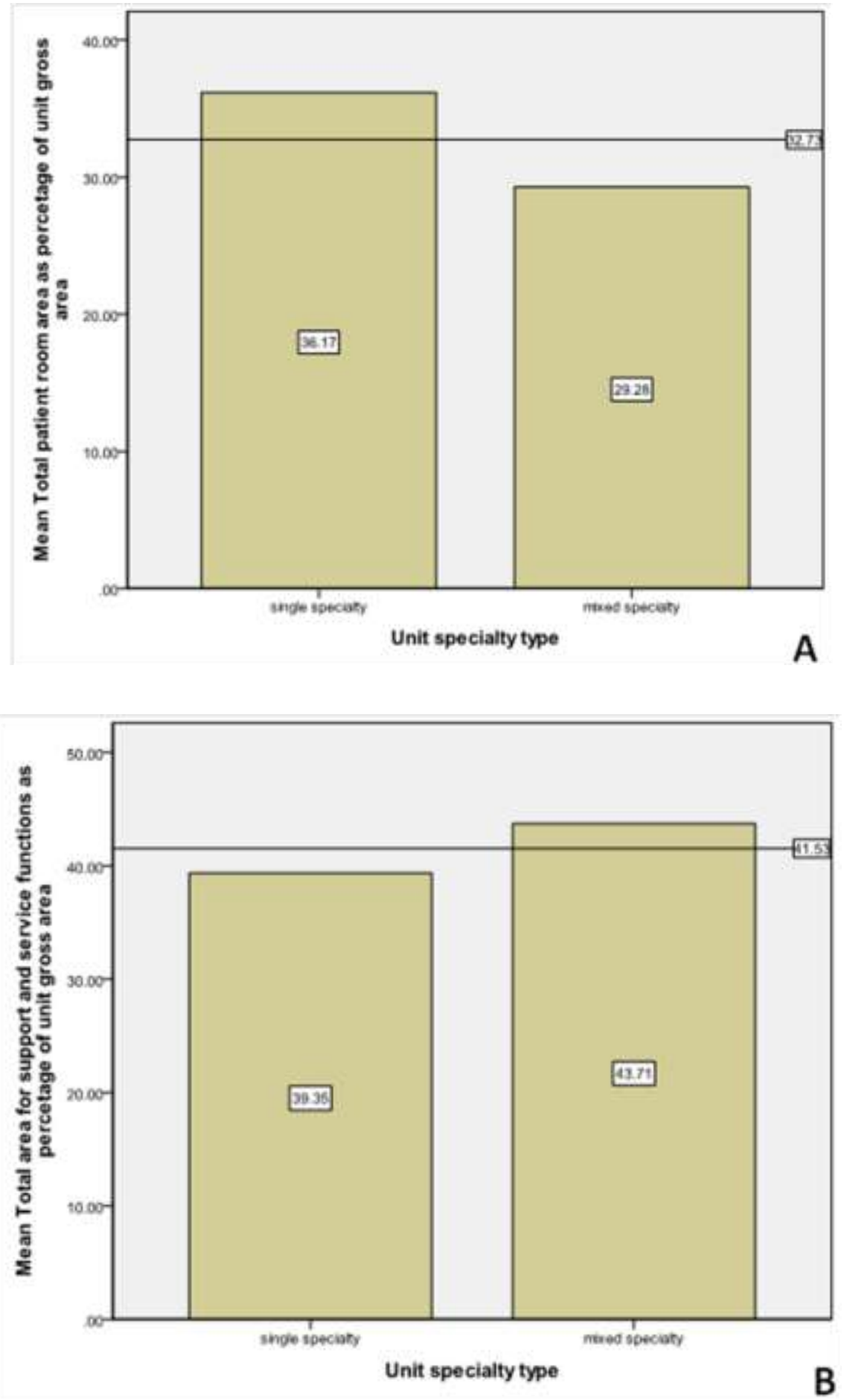


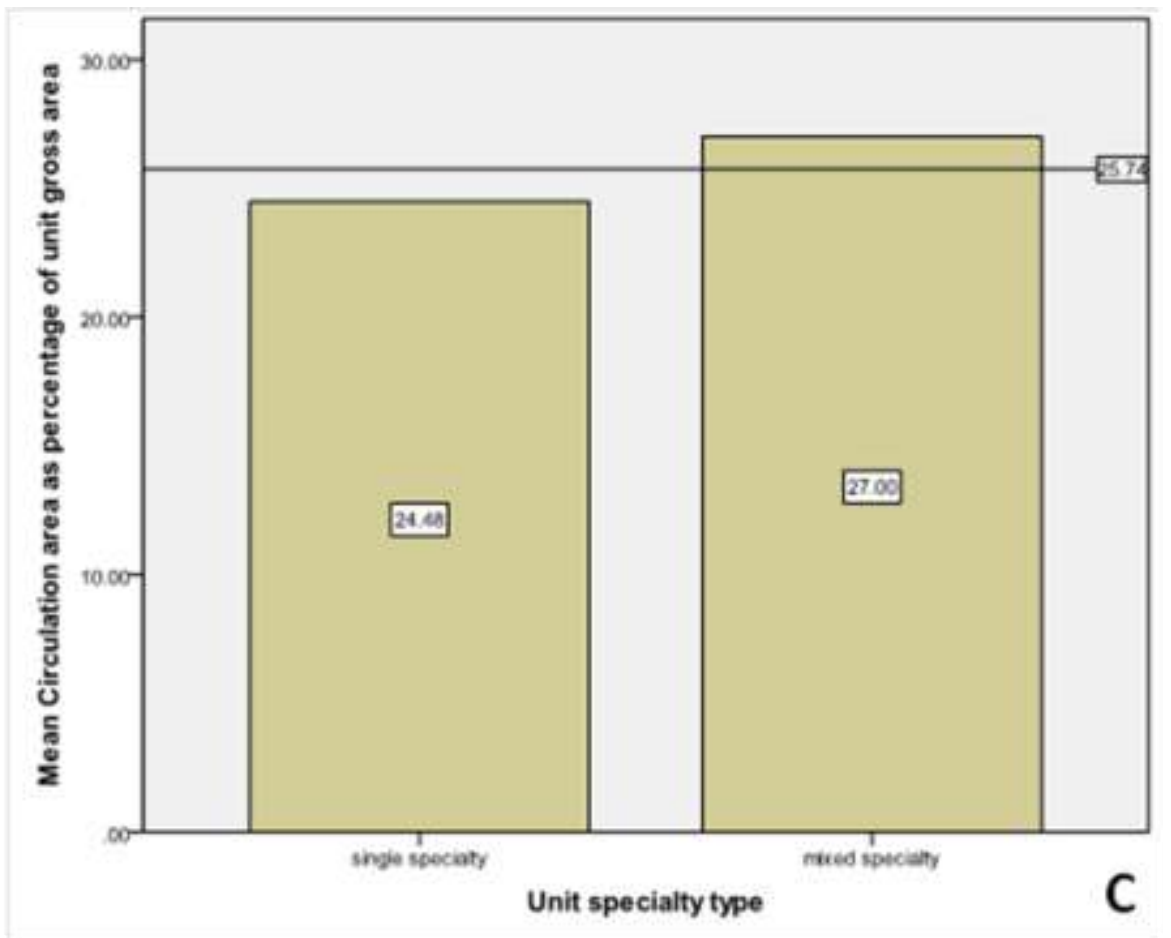

Figure 9: Allocation of space by unit specialty type. A) Mean total patient room area as percentage of unit gross area. B) Mean total area for support and service functions as percentage of unit gross area. C) Mean total circulation area as percentage of unit gross area.

\section{UNIT LAYOUT TYPE \& SPACE ALLOCATION}

ICUs, like any other hospital inpatient units, can be designed to have different layouts. Among the more commonly used layouts are racetrack layout, single- or double-corridor layout, open-plan layout, radial layout and some combinations or variations of these layouts. Several of these common unit layouts are shown in Figure 10 (reproduced from James and Tatton-Brown, 1986). Even though some studies show that radial units perform better than single- and/or double-corridor units due to better visibility and shorter walking (for example, see Shepley \& Davies, 2003; Sturdavant, 1960; Trites et al., 1970), systematic studies comparing all different types of unit layout in terms of systems, group and person-related outcomes are still missing. 
This study finds that, among the 1993-2002 ICUs, $66.67 \%$ were the racetrack type units; $13.33 \%$ were the open-plan layout units; $0 \%$ was the corridor type units; $6.67 \%$ were the radial layout units; and $13.33 \%$ were the mixed layout units. In contrast, among the 2003-2012 ICUs, $80 \%$ were the racetrack type units; $10 \%$ were the open layout units; $10 \%$ were the corridor type units; $0 \%$ was the radial layout units; and 0\% was the mixed layout units (Figure 11). These findings indicate that there were more variations in unit layout types in the first decade than there were in the second decade. The findings also indicate that [THE RACETRACK TYPE HAS BEEN THE MOST DOMINANT UNIT TYPE AMONG THE AWARD-WINNING ADULT ICUS DURING THE LAST TWO DECADES ACCOUNTING FOR

73.33\% OF ALL THE UNITS] the racetrack type has been the most dominant unit type among the bestpractice example adult ICUs during the last two decades accounting for $73.33 \%$ of all the units.

The appeal of the racetrack type unit may be due to the perception that it provides more perimeter wall for more patient rooms with natural light and outside view; that it accommodates more compact and centralized support and service areas which is optimal for care and care-related functions; and that it helps reduce the physical distance from patient rooms to support and service areas. In contrast, since corridors in a racetrack type layout wrap around and cut across a core of support and service areas, it may force staff to walk more despite the perception that it helps reduce the physical distance from patient rooms to support and service functions. Some evidence supporting these claims was found in the study of space allocation in the award-winning ICUs discussed below. 


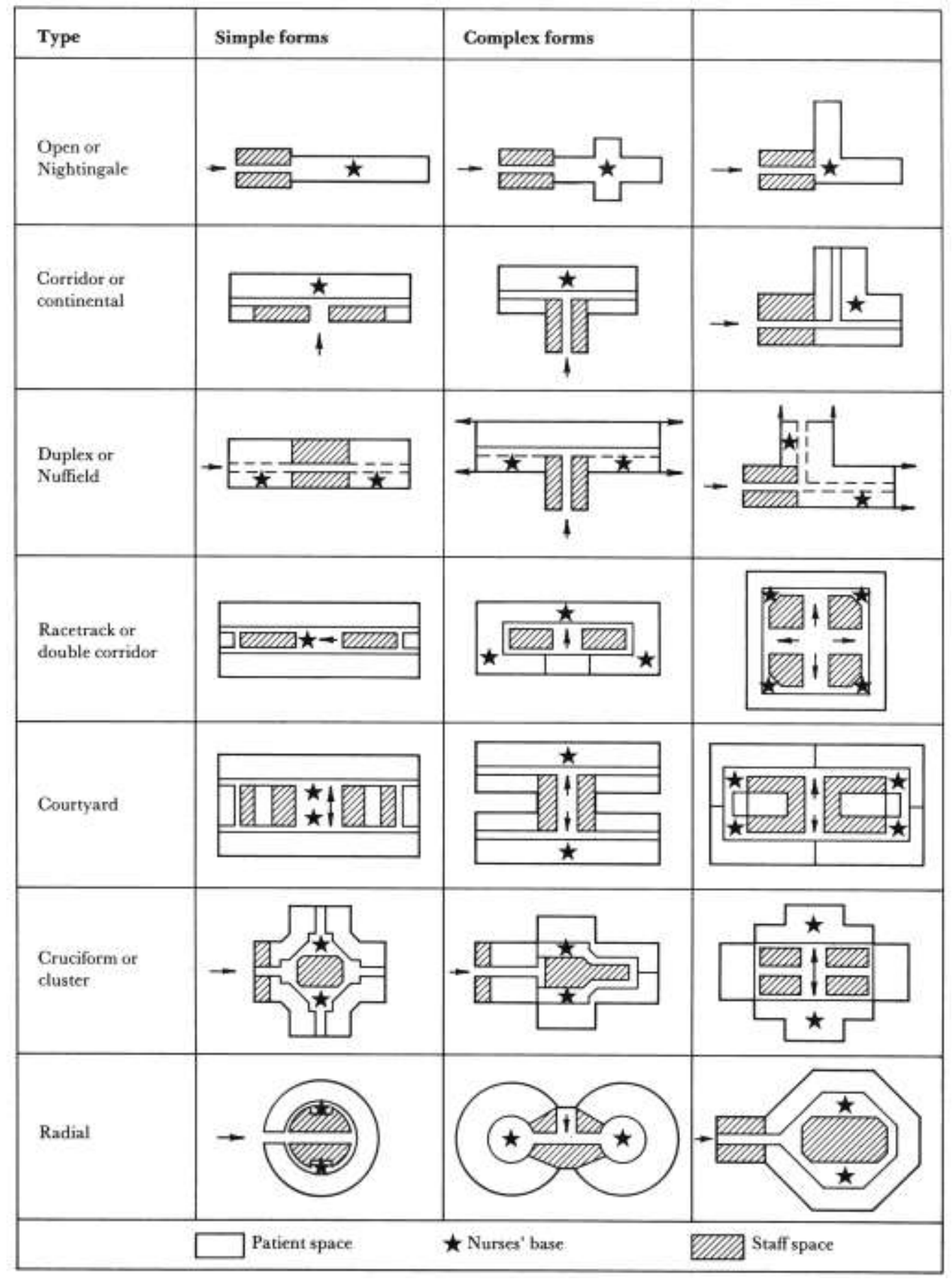

Figure 10: Different types of unit layout. [Source: James and Tatton-Brown, 1986. With permission from Elsevier.] 


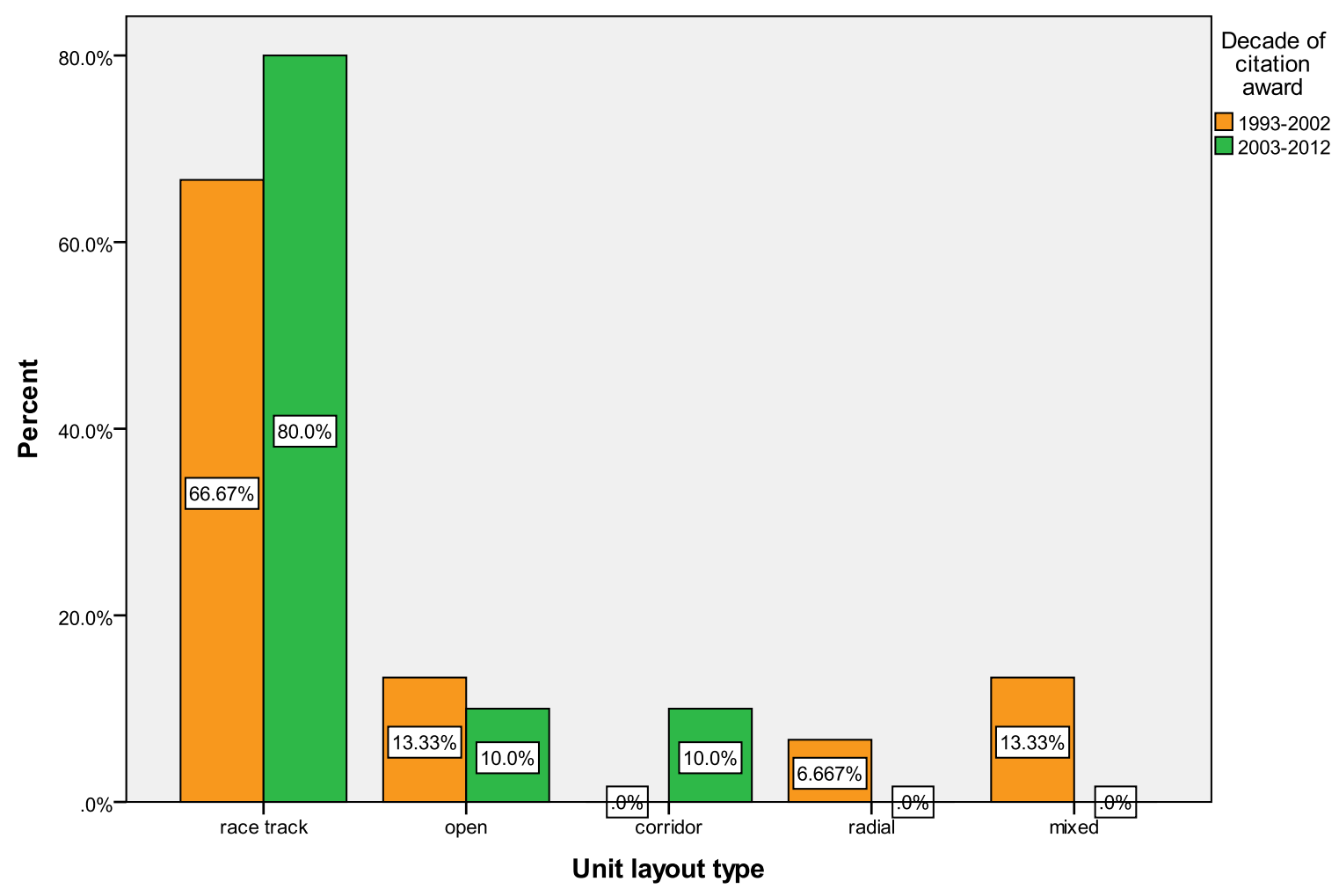

Figure 11: Different types of unit layout by decade.

There was only one radial unit type layout in the sample with a large unidentified space in the center. Leaving the unit out of the sample, the overall space allocation as represented by the mean of the approximate gross area per patient bed for open-plan layout was the highest (912.5 square feet); followed by the racetrack layout (864.2 square feet); the mixed layout type was the next (846.4 square feet); and the corridor type layout was the lowest (692.3square feet) (Figure 12). These differences in the approximate gross area per patient bed among the unit layout types might have been significant in dollar amounts for large units. 


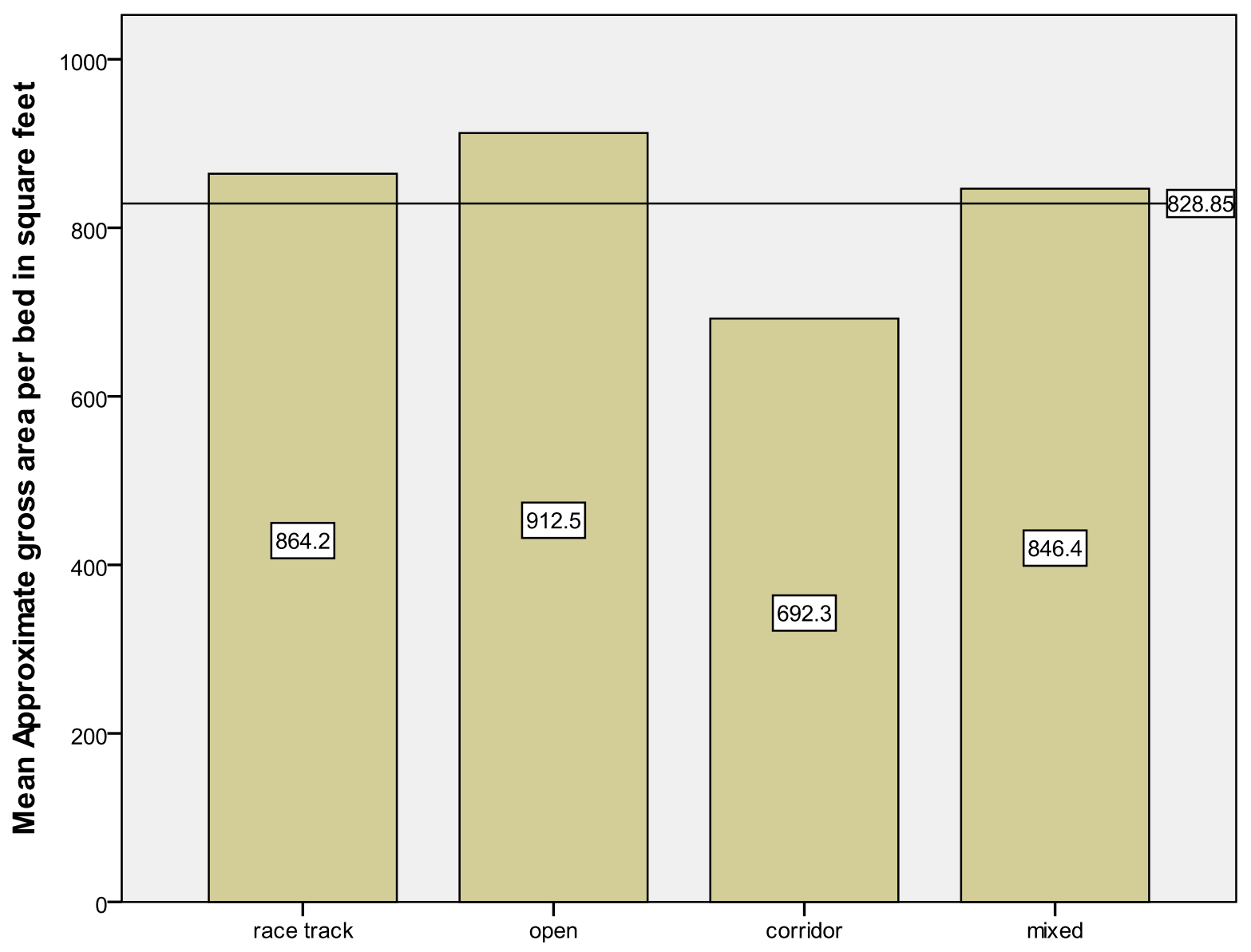

\section{Unit layout type}

Figure 12: Mean approximate gross area per bed by unit layout type.

Since about $75 \%$ of all award-winning ICUs included in the study had a racetrack type layout, space allocation among different generic categories of functions in the layout type needed attention. The study found that the racetrack type units had the highest mean of the total patient room area as percentage of unit gross area among all the unit types (Figure 13A) supporting an earlier claim that the layout might provide most space for patient rooms.

The study also found that the racetrack type units had the lowest mean of the total support and service areas as percentage of unit gross area among all the unit types (Figure 13B) supporting another earlier claim that support and service areas would be more compact in the layout. Less support and service areas in racetrack type units, however, should not imply that these units provided fewer services. In today's 
ICUs, services are often decentralized and many are being provided in larger patient rooms. Sometimes, improved technology also reduces the amount of space needed for a service. As a result, the level of care and the amount of services in ICUs may not be directly associated with the amount of area given to service and support functions in ICUs.

Additionally, the study found that the racetrack type units had the highest mean of the total circulation areas as percentage of unit gross area among all the unit types (Figure 13C) supporting yet another earlier claim that a racetrack type layout might require more circulation spaces. More studies are required to understand how these aspects of a unit layout type affect patient care and other outcomes.

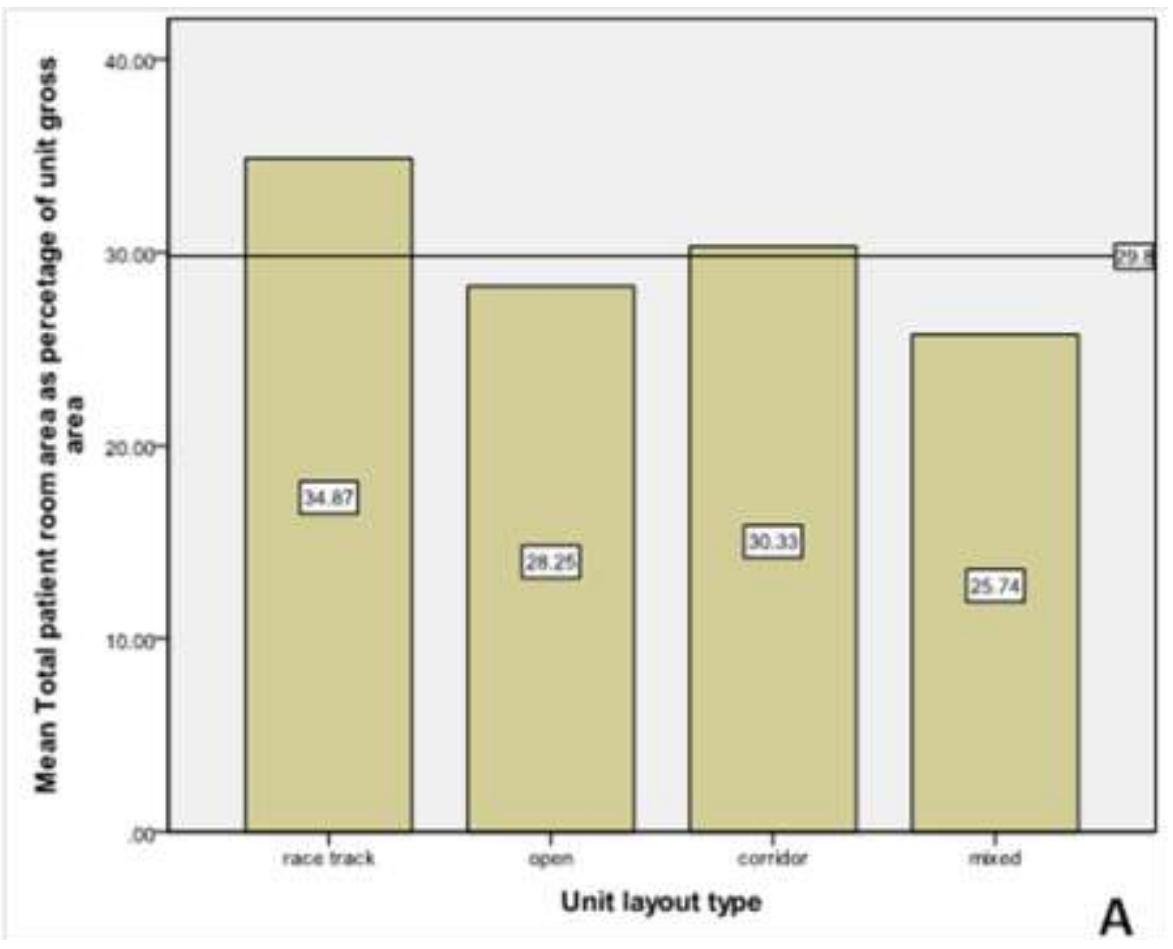



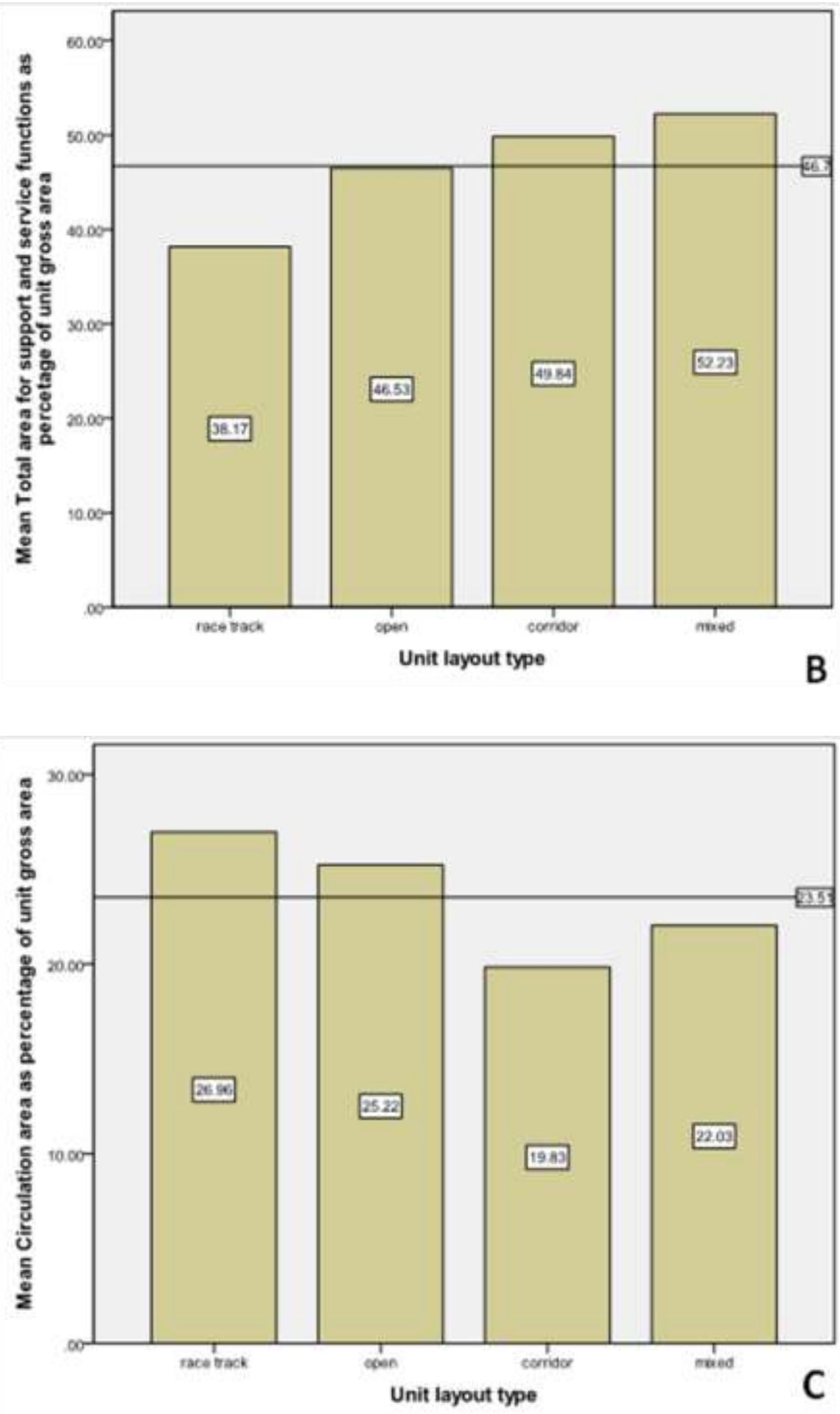
Figure 13: Allocation of space by unit layout type. A) Mean total patient room area as percentage of unit gross area. B) Mean total area for support and service functions as percentage of unit gross area. C) Mean total circulation area as percentage of unit gross area.

\section{PATTERNS IN SPACE ALLOCATION AMONG DIFFERENT GENERIC FUNCTIONS}

A correlational analysis showed how the size of the unit in square feet (that is, the unit gross area), and space allocation among different generic categories of functions - patient room areas, support and service areas, and circulation areas - are related to one another and to the number of beds in the unit (Table 1).

\begin{tabular}{|c|c|c|c|c|c|c|}
\hline & $\begin{array}{l}\text { Number } \\
\text { of beds in } \\
\text { the unit }\end{array}$ & $\begin{array}{l}\text { Approximate } \\
\text { unit size in } \\
\text { square feet }\end{array}$ & $\begin{array}{l}\text { Approximate } \\
\text { gross area } \\
\text { per bed in } \\
\text { square feet }\end{array}$ & $\begin{array}{l}\text { Total } \\
\text { circulation } \\
\text { area as } \\
\text { percentage } \\
\text { of unit } \\
\text { gross area }\end{array}$ & $\begin{array}{l}\text { Total patient } \\
\text { room area as } \\
\text { percetage of } \\
\text { unit gross } \\
\text { area }\end{array}$ & $\begin{array}{l}\text { Total area for } \\
\text { support and } \\
\text { service } \\
\text { functions as } \\
\text { percetage of } \\
\text { unit gross } \\
\text { area }\end{array}$ \\
\hline Number of beds in the unit & 1 & 1 & & & & \\
\hline Approximate unit size in square feet & $.639^{*+}$ & 1 & & & & \\
\hline Approximate gross area per bed in square feet & & $.787^{\text {kt }}$ & 1 & & & \\
\hline Total circulation areas as percentage of unit gross area & & & & 1 & 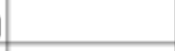 & \\
\hline Total patient room areas as percentage of unit gross area & & $-.517^{* *}$ & $-.674^{* *}$ & & 1 & \\
\hline $\begin{array}{l}\text { Total area for support and service functions as percetage of unit } \\
\text { gross area }\end{array}$ & & $496^{*}$ & $.629^{\star \star}$ & $-.509^{\star *}$ & $-.896^{\star *}$ & 1 \\
\hline
\end{tabular}

* Correlation is significant at the 0.05 level (2-tailed).

${ }^{*}$ Correlation is significant at the 0.01 level (2-tailed).

Table 1: Correlation matrix.

The analysis found a significant positive correlation between the number of beds in the units and the gross area of the units $(r=0.639 ; \mathrm{p}<.01)$ indicating that as the number of beds increases so does the size of the units (also see the scattergram in Figure 14). Though a simple regression model showed that the predictive power $\left(\mathrm{r}^{\wedge} 2\right)$ of the number of beds in the unit over the gross area have decreased from 0.49 in a previous study (Rashid, 2006) to 0.4 in the present study, the pattern seemed to have persisted over the 
last two decade between 1993 and 2012. The finding that the gross area of the units might be a function of the number of beds in the units was also supported by a significant positive correlation between the gross area per bed and the gross area of the units $(r=0.787 ; \mathrm{p}<.01)$ indicating that as the gross area of the units increases so did the gross area per bed in the units or vice versa. Therefore, the present study supports the observation that the ICUs with more beds had larger gross area.

The analysis also found a significant negative correlation between the patient room areas and the gross area of unit $(\mathrm{r}=-0.517 ; \mathrm{p}<.01)$ and between the patient room areas and the gross area per bed $(\mathrm{r}=-0.674$; $\mathrm{p}<.01$ ). These findings indicate that as the gross area of the unit and the gross area per bed increased the patient room area decreased in this sample of ICUs. This is interesting in light of the findings that showed as the number of beds increased so did the size of the unit. In simple words, even though unit size increased due to an increase in bed number, paradoxically bigger units with more beds had smaller area for patient rooms.

Additionally, the analysis also found a significant positive correlation between the total support and service areas and the gross area of unit $(\mathrm{r}=0.496 ; \mathrm{p}<.05)$ and between the total support and service areas and the gross area per bed $(\mathrm{r}=0.629 ; \mathrm{p}<.01)$. These findings indicate that as the gross area of the unit and the gross area per bed increased the support and service area also increased. In simple words, bigger units with more beds had bigger support and service areas.

Finally, the analysis found a significant negative correlation between the total support and service areas and the circulation areas $(r=-0.509 ; \mathrm{p}<.01)$ and between the total support and service areas and the patient room areas $(\mathrm{r}=-0.896 ; \mathrm{p}<.01)$. These findings indicate that as the patient room area and the circulation area of the unit increased the support and service area decreased in these award-winning ICUs. In simple words, these award-winning ICU made their support and service areas smaller in order to make patient rooms and circulation spaces bigger. 


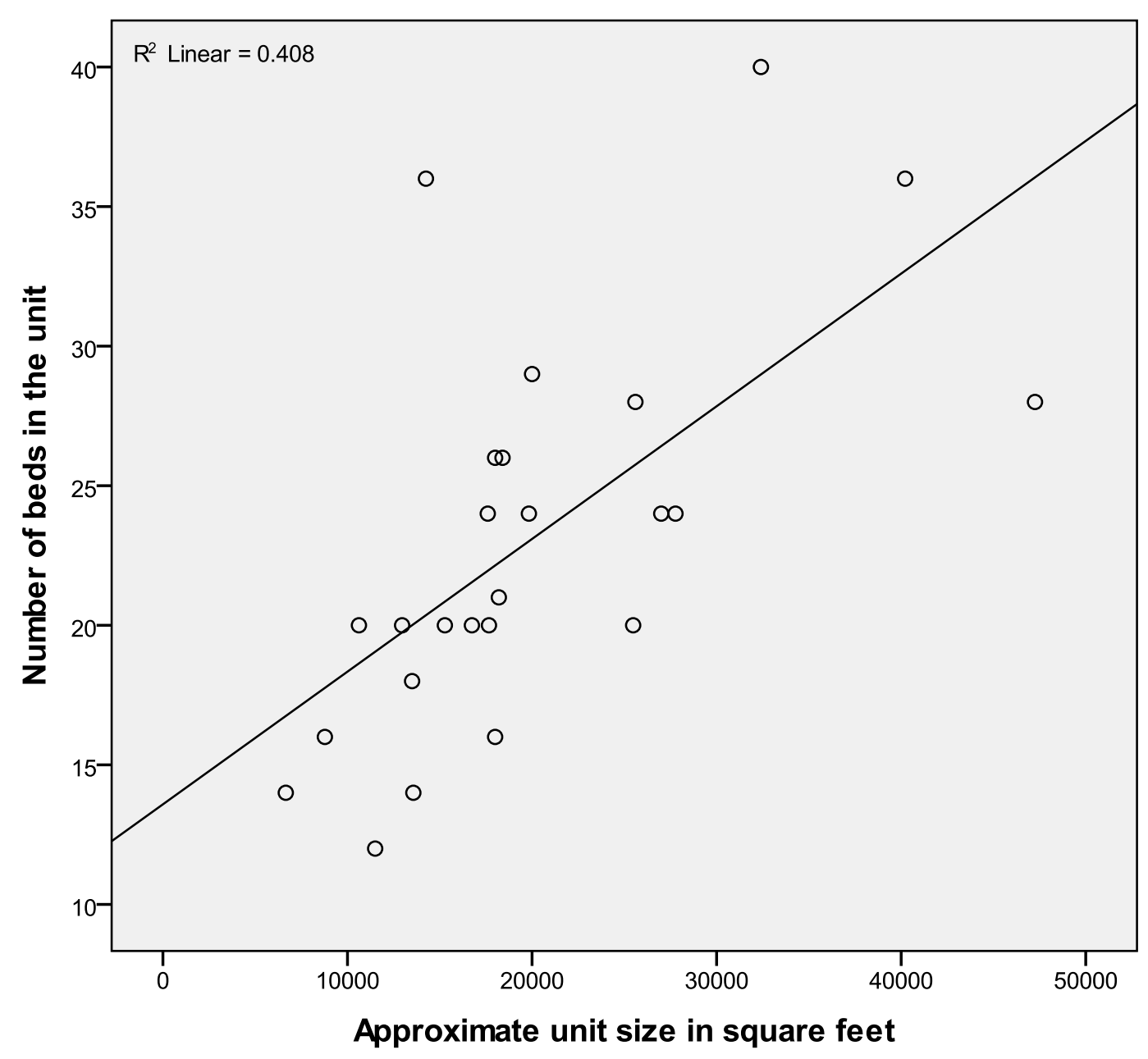

Figure 14: Scattergram showing the correlation between the number of unit beds and the approximate unit size.

\section{SUMMARY, LIMITATIONS, \& CONCLUSION}

The study looked at the patterns of space allocation in the award-winning ICUs of the last two decades from 1993-2012. It showed how the amount of space of any one functional category might be related to that of another functional category in these ICUs. It also showed how some of the very early strategic design choices affect space allocation in the award-winning ICUs. Since these exemplary ICUs were able to improve their outcomes through design, we can only expect that the lessons learnt from these examples would help create better design for improved outcomes. There was no attempt made in this paper to 
independently verify if the design tactics used in the best practice examples would indeed improve outcomes.

With regards to space allocation in these units by decade, the study made the following observations:

1) The mean of the approximate gross area per patient bed decreased in the ICUs of the second decade; and

2) The mean of the total patient room area as percentage of the unit gross area increased, but the means of circulation area and support and service areas as percentages of the unit gross area decreased in the ICUs of the second decade.

With regards to space allocation in these ICUs by construction type, the study made the following observations:

1) The mean of the approximate gross area per patient bed was the highest in the new units, followed by the renovated units, and it was the least in the part-new and part-renovated units; and

2) The patterns of space allocation among different generic categories of functions - patient room area, support and service area, and circulation area - were different in ICUs with different types of construction.

With regards to space allocation in these ICUs by specialty type, the study made the following observations:

1) The mean of the approximate gross area per patient bed for the single-specialty units was less than the mixed-specialty units;

2) In the mixed-specialty units a greater need for more circulation, support, and service areas was met by reducing the area for patient rooms. In contrast, a need for less circulation, support, and service areas in single specialty units might have translated into more area in patient rooms. 
The study also looked at how the unit gross area and space allocation among different generic categories of functions were related to one another and to the number of beds in the unit in the award-winning adult ICUs built between 1993 and 2012. Based on a correlational analysis, the study made the following observations:

1) The ICUs with more beds generally had larger gross area;

2) Larger units with more beds had smaller areas for patient rooms;

3) Bigger units with more beds had bigger support and service areas; and

4) As patient rooms and circulation areas of the unit increased the support and service area decreased in these ICUs.

The study is a valuable start with regards to our understanding of space allocation patterns in adult ICUs. However, there is a need to study a bigger sample to reach any definitive conclusions. Future studies should also include ICUs that did not win awards to understand if space allocation in the no-award group is any different from that in the award-winning group.

Inconsistent drawings were another limitation of the study. In the future, it may be necessary to work with the AutoCAD drawings of these ICUs for accuracy. Since most available AutoCAD drawings may not show the existing state of these ICUs, site verifications may be required.

The study was limited to studying the three generic categories of spaces to minimize arbitrary decisions concerning space allocation. More specific knowledge about space allocation could be gained if more extensive categories of spaces were considered in the study. These categories could include different types of patient rooms, different types of circulations spaces, different types of support and service spaces including staff support area, administration and academic areas, family support areas, and storage spaces.

Concerning unit specialty, the study grouped the sample of ICUs in two simple types - single-specialty and mixed-specialty units. As noted earlier, ICUs can be designed to serve many different specialty and 
subspecialty. Future studies should look at the ICUs of each specialty type to understand the similarities and differences in space allocation in each type.

Other potential topics for further research may include the impact of decentralization of services on space allocation in ICUs. These studies may help show how the level of decentralization involving supplies, equipment and medications to support point of care services affects space allocation in ICUs. Yet other topics may include the impact of technology - mobile devices and virtual medicine - on ICU spaces. These studies may help show how the level of technology integration affects space allocation in ICUs.

Despite several limitations, this study involving 25 award-winning adult ICUs was the most extensive among the studies so far reported in the literature on space allocation in ICUs. Since these award-winning ICUs also represent most recent examples of best-practice, the study provides evidence for allocating space in a manner that may help create better ICUs now. More particularly, the study may help improve functional dependencies in ICUs because it shows how the amount of space of any one generic category of function may be related to that of another generic category of function in the award-winning ICUs. The study may also help make better strategic choices because it shows how different strategic choices, such as unit size, construction type, unit specialty, and layout type, affect space allocation in the awardwinning ICUs. Additionally, the study may help guide the evolution of ICU design at a time of great change and innovation because it shows how space allocation has changed in the award-winning ICUs of the last two decades.

\section{IMPLICATIONS FOR PRACTICE}

Despite several limitations, this study involving 25 award-winning adult ICUs was the most extensive among the studies so far reported in the literature on space allocation in ICUs. Since these award-winning ICUs also represent most recent examples of best-practice, the study provides evidence for allocating space in a manner that may help create better ICUs now. More particularly, the study may help improve functional dependencies in ICUs because it shows how the amount of space of any one generic category 
of function may be related to that of another generic category of function in the award-winning ICUs. The study may also help make better strategic choices because it shows how different strategic choices, such as unit size, construction type, unit specialty, and layout type, affect space allocation in the awardwinning ICUs. Additionally, the study may help guide the evolution of ICU design at a time of great change and innovation because it shows how space allocation has changed in the award-winning ICUs of the last two decades. 


\section{REFERENCES}

Allison, D., \& Hamilton, K. (2008). Analysis of Departmental Area in Contemporary Hospitals:

Calculation Methodologies \& Design Factors in Major Patient Care Departments. Final Report, January 24, 2008. Conducted with grants from: Frank Zilm \& Associates, Inc., Academy of Architecture for Health Foundation, McKahan Planning Group, and American College of Healthcare Architects.

Archibald, L. K., Manning, M. L., Bell, L. M., Banerjee, S., Jarvis, W.R. (1997). Patient density, nurseto-patient ratio and nosocomial infection risk in a pediatric cardiac intensive care unit. Pediatric Infectious Disease Journal, 16(11), 1045-1048.

Bartley, J. M., Olmsted, R. N., Haas, J. (2010). Current views of health care design and construction: Practical implications for safer, cleaner environments. Am J Infect Control, 38, S1-S12.

Borg, M. A. (2003). Bed occupancy and overcrowding as determinant factors in the incidence of MRSA infections within general ward settings. Journal of Hospital Infection, 54, 316-318.

Cadenhead, C., Anderson, D. (2009). Critical care unit design, the winners and future trends: An investigative study. World Health Design Journal, 2, 72-77.

Carter, C. D., Barr, B. A. (1997). Infection control issues in construction and renovation. Infect Control Hosp Epidemiol., 18(8), 587-596.

Carthey, J. (2008). Reinterpreting the Hospital Corridor: "Wasted Space" or Essential for Quality Multidisciplinary Clinical Care? HERD - Health Environments Research Journal, Autumn, 2(1), 17-29.

Goodley, J. M., Clayton, Y. M., Hay, R. J. (1994). Environmental sampling for aspergilli during building construction on a hospital site. J Hosp Infect., 26(1), 27-35.

Hamilton, D. K. (1999). Design for flexibility in critical care. New Horizons, 7, 205-217.

Hamilton, D. K. (2000, Ed.) ICU 2010: ICU Design for the Future, a Critical Care Design Symposium. Center for Innovation in Health Facilities, Houston.

Hamilton, D., Shepley, M. (2010). Design for Critical Care: An Evidence-based Design Approach. Architectural Press/Elsevier, Oxford, UK.

IBM Corp. (Released 2011). IBM SPSS Statistics for Windows, Version 20.0. Armonk, NY: IBM Corp. 
Iwen, P. C., Davis, J. C., Reed, E. C., Winfield, B. A., Hinrichs, S. H. (1994). Airborne fungal spore monitoring in a protective environment during hospital construction, and correlation with an outbreak of invasive aspergillosis. Infect Control Hosp Epidemiol., 15(5), 303-306.

James, W. P., Tatton-Brown, W. (1986). Hospitals: Design and Development. The Architectural Press, London.

National Institute of Health. (1983). NIH Consensus Development Conference on critical care medicine. Crit Care Med, 11, 466-469.

Oren, I., Haddad, N., Finkelstein, R., Rowe, J. M. (2001). Invasive pulmonary aspergillosis in neutropenic patients during hospital construction: Before and after chemoprophylaxis and institution of HEPA filters. American Journal of Hematology, 66(4), 257-262.

Rashid, M. (2006). A decade of adult intensive care unit design: A study of the physical design features of the best-practice examples. Cit Care Nurs Q, 29(4), 282-311.

Society of Critical Care Medicine (SCCM), American Association of Critical Care Nurses (AACN), and American Institute of Architects (AIA). (2012). Award Winning ICU Designs: How to build a better facility for patients and caregivers. Society of Critical Care Medicine.

Society of Critical Care Medicine. (1995). Guidelines for intensive care unit design. Crit Care Med, 23, $582-588$.

Shepley, M. M., Davies, K. (2003). Nursing unit configuration and its relationship to noise and nurse walking behavior: An AIDS/ HIV unit case study. AIA Academy Journal [Retrieved 0n 04 August 2012 from http://www.aia.org/groups/aia/documents/pdf/aiab090850.pdf]

Sturdavant, M. (1960). Intensive nursing service in circular and rectangular units. Hospitals-JAHA, 34, 46-48, 71-78.

Shortell, S. M., Zimmerman, J. E., Rousseau, D. M., et al. (1994). The performance of intensive care units: Does good management make a difference? Medical Care, 32 (5), 508-525.

The Facility Guidelines Institute. (2010). Guidelines for Design and Construction of Health Care Facilities. The Facility Guidelines Institute, Chicago, IL.

Thompson, D. R., Hamilton, D. K., Cadenhead, C. D., et al. (2012). Guidelines for intensive care unit design. Crit Care Med., 40(5), 1586-1600. 
Trites, D. K., Galbraith, F. D., Sturdavant, M., Leckwart, J. F. (1970). Influence of nursing-unit design on the activities and subjective feelings of nursing personnel. Environment \& Behavior, 2(3), 303-334.

Vincent, J. L., Bihari, D. J., Suter, P. M., et al. (1995). The prevalence of nosocomial infection in intensive care units in Europe. JAMA, 274, 639-644. 